\title{
The impact of thermal transmittance variation on building design in the Mediterranean region
}

\author{
Marco S. Fernandes ${ }^{a, *}$, Eugénio Rodrigues ${ }^{\mathrm{a}, \mathrm{b}}$, \\ Adélio Rodrigues Gaspar ${ }^{\mathrm{a}}$, José J. Costa ${ }^{\mathrm{a}}$, Álvaro Gomes ${ }^{\mathrm{b}, \mathrm{c}}$ \\ ${ }^{a}$ ADAI, LAETA, Department of Mechanical Engineering, University of Coimbra \\ Rua Luís Reis Santos, Pólo II, 3030-788 Coimbra, Portugal \\ ${ }^{b}$ INESC Coimbra - Institute for Systems Engineering and Computers in Coimbra \\ Rua Silvio Lima, Pólo II, 3030-290 Coimbra, Portugal \\ ${ }^{c}$ Department of Electrical and Computer Engineering, University of Coimbra \\ Rua Silvio Lima, Pólo II, 3030-290 Coimbra, Portugal
}

\begin{abstract}
Contrarily to what happens in northern European countries, buildings in the Mediterranean region are prone to overheating. Consequently, it is important to better understand the role of thermal transmittance of the building envelope elements in the air-conditioning consumptions. This paper analyzes the effect of different $U$-values on the building design in the Mediterranean area. 192000 residential buildings were randomly generated and the energy consumption assessed for sixteen distinct locations. It was found that, in northern Mediterranean locations, as $U$-values decrease, the energy consumption also decreases. However, in warmer climates, low thermal transmittances tend to significantly increase the energy consumption. Hence, the lower the latitude, the higher the most adequate $U$-values, due to the increase of the cooling demands. Additionally, geometry-based indexes were correlated with the buildings energy performance. For high $U$-values it was found that bigger buildings worsen the energy performance and larger windows tend to improve it. For low $U$-values, bigger North-faced windows are beneficial. There is an adequate interval of values for which the geometry has a lower impact, which is wider and higher for lower latitudes, thus meaning that not only the building performance improves but architects are also freer to explore alternative designs.
\end{abstract}

Keywords: generative design method, dynamic simulation, residential buildings, building geometry, thermal transmittance, Mediterranean climates

\section{Nomenclature}

$C_{f} \quad$ Shape coefficient

$R C \quad$ Relative compactness

\footnotetext{
${ }^{*}$ Corresponding author.

Email address: marco.fernandes@adai.pt (Marco S. Fernandes)
} 
U Thermal transmittance

$V \quad$ Building volume

WFR Window-to-floor ratio

WSR Window-to-exterior surface ratio

$W W R \quad$ Window-to-wall ratio

EPSAP Evolutionary Program for the Space Allocation Problem

HVAC Heating, Ventilation and Air-Conditioning

\section{Introduction}

Energy consumption in the building sector continues to increase worldwide. More specifically, buildings account for one-third of today's final energy consumption, with households accounting for about three-quarters [1. This adds to the fossil fuels depletion and to the climate change, thus making the reduction of energy consumption in the building sector of crucial importance. However, this sector is also considered one of the most cost-effective areas to reduce energy use [2]. In this context, some authors have already pointed out that the traditional thermal transmittance of building envelope elements may not be the most appropriate [2 6 . Inadequate $U$-values for opaque and transparent elements may lead to higher heating and/or cooling demands, thus worsening the buildings' performance.

In the particular case of the Mediterranean region, buildings are more prone to overheating than in northern European countries, thus leading to higher cooling demands; which is a rare issue in those countries. There are several studies regarding the optimal energy performance values for the envelope elements of buildings in the Mediterranean region: for example, Tsikaloudaki et al. [7] assessed the window's contribution to the energy performance of buildings in the warmer regions of Europe. The authors carried out a parametric study by varying the window's glazing area, $U$-value, and $g$-value in a reference room with residential and office use profiles. The authors concluded that for the cooling mode the energy performance of windows is influenced significantly by their thermophysical properties, and that fenestration elements with low thermal transmittance seem to have a detrimental impact in the energy performance, since it prohibits the dissipation of heat toward the ambient environment and results in higher cooling demands. Marino et al. [8] performed a parametric study on the effect of the window-to-wall ratio $(W W R)$ on the energy consumption of the Italian building stock. The authors concluded that albeit energy consumption demonstrated 
to be strongly influenced by climate conditions, insulation features of the structures, facade configurations, presence of shading devices, the optimal $W W R$ does not seem to vary remarkably if the effect of each factor is assessed individually. On the other hand, regardless the climate conditions, the optimal $W W R$ may be doubled for the simultaneous effect of an improvement of the envelope features and of an enhancement of the installed lighting electric power. Amaral et al. [9] performed a parametric study of a reference room where the window size, orientation, and shadowing are analyzed for three types of glazing in Coimbra, Portugal. The authors concluded that lower $U$-values of the windows contributes to have smaller windows facing south, west, and east orientations and larger windows facing north; being the south orientation the one which contributes higher to the space thermal performance. As these studies point out, it is of interest to determine the proper relation between the elements' $U$-values and the buildings' energy consumption, as well as the correlation of geometry-based indexes (e.g., shape coefficient, window ratios) with the $U$-values. These indexes, when correlated with the energy consumptions, can be useful to draw guidelines that point out the way for better building performances [9-15], thus helping designers to explore alternative forms and designs. In the specific case of Mediterranean climates, it is interesting to understand which are the most adequate thermal transmittance values of the buildings' elements that decrease the heating demands without excessively raising the cooling needs.

Parametric studies, as the ones presented above, are useful when the decision variables are in a small number. However, if these increase, optimization methods are more adequate, especially when dealing with non-linear problems and more than one objective. For instance, Baglivo et al. [16] carried out a multi-objective optimization analysis for high energetic efficiency external walls of zero energy building in the Mediterranean climate, through the combination of various materials with different thermophysical properties. The results showed that the superficial mass of the external wall is important to obtain the best performance in the warm climate, and that is possible to reach high performance in the summertime also by lighter and thinner walls. Echenagucia et al. [17] proposed an integrative approach for the early stages of building design to obtain detailed information on energy efficient envelope configurations, consisting of a multi-objective search with the aim of minimizing the energy need for heating, cooling and lighting. The investigation was carried out for an open space office building in four European locations. The results highlighted a small overall $W W R$ of the building in all locations, especially in east, west and north exposed facades. The area of the south facing windows was higher compared to the other orientations and characterized by a higher variability. Ascione et al. [18] presented an integrated design procedure focusing on the problem of a large number of available building envelope variants concerning the multi-objective optimization of residential nearly-zero energy buildings (nZEB) in four Mediterranean locations. The results showed that for minimizing heating and cooling demands, highly 
insulated walls and roofs are required. Also, for lower latitudes in the Mediterranean Sea region, the optimal wall $U$-values for Winter and Summer tend to be smaller. However, there is no defined tendency when the aim is to reduce the overall energy demand. On the other hand, the optimal $U$-value for the roof element was found to be constant when minimizing the overall energy demand. Goia [12] used a sequential simulation procedure to determine the optimal $W W R$ in office buildings for different European climates (including Rome and Athens in the Mediterranean region) and its implication in the total energy saving. The author concluded that most of the ideal $W W R$ values are found in the range of 0.30 to 0.45 . Moreover, it was concluded that the total energy demand may increase by $5 \%-25 \%$ when the worst $W W R$ is adopted. The same author and his research group have also applied the same methodology in the search for the optimal transparent percentage in a facade module for low energy office buildings in a temperate oceanic climate [19]. The results showed that, regardless of the orientations and of the facade area of the building, the optimal configuration is achieved when the transparent percentage is between $35 \%$ and $45 \%$ of the total facade module area. The highest difference between the optimal configuration and the worst one occurs in the north-exposed facade, while the south-exposed facade is the one that shows the smallest difference between the optimal and the worst configuration. Cascone et al. 20] presented multi-objective optimization analyses for the energy retrofitting of office buildings in Mediterranean climates with PCM-enhanced opaque building envelope components. The search variables included the thickness and thermophysical properties of the PCM layers, the window type, the insulation and internal lining materials, the wall configuration and $U$-value. The authors concluded that the PCM layer in the wall should be placed at the closest position to the internal environment, and that the optimal thermo-physical properties of PCMs were found to be affected in particular by the operation of the HVAC system. In addition, a low $U$-value was found to be particularly important for the case of a retrofitting intervention on the internal side in order to minimize both the primary energy consumption and the global costs. Besides, the authors concluded that the use of aerogel insulation, in the case of retrofitting on the external side, was found to reduce the primary energy consumption as a result of a reduced shading in winter, but higher investment costs would be induced by such a choice. A further general literature review on optimization analyses regarding the energy performance enhancement of buildings can be found in refs. [21 25].

As it can be perceived in the above-referenced research works, the available studies perform parametric studies or optimization procedures to determine some optimal value of some variables related to windows or exterior walls, which were tested in a reference room or a single building geometry. Therefore, the generalization of the conclusions should be careful, as these are specific to the showcase in analysis. In the approach presented in this paper, it is carried out a statistical analysis of a large dataset of randomly generated building geometries with randomly assigned 
$U$-values to opaque and transparent envelope elements. This approach prevents geometry-biased results from using a single building. Therefore, the results are general $U$-values for each location for the studied type of buildings; hence, these can be used as initial values in optimization procedures for a specific building geometry, thus narrowing the search space and speeding the search process by being nearer to the optimal solution. The dataset is also partitioned into subgroups according to each $U$-value and correlated to several geometry-based indexes, thus allowing to delineate design guidelines for more energy efficient buildings, as they can capture the relation of some geometric variables with the performance of the building [14], while serving as support and guide to building designers when opting for certain construction system with specific level of insulation. In addition, in the particular case of the Mediterranean region, the available research works usually address only the European side of the Mediterranean, thus not providing a complete assessment of the entire region. This work tries to fill that gap, by presenting an overall assessment in several locations throughout the Mediterranean - including South Europe, North Africa and the Middle East.

The main goal of this paper is thus to assess the effect of different $U$-values of the building envelope elements from an energy performance and a building geometry perspective, in distinct Mediterranean locations. The analysis covers a large dataset of randomly generated building geometries for each location, assessing the most suitable thermal transmittance values of the buildings' elements that decrease their energy consumption, while also resulting in some design guidelines based on the correlation of geometry-based indexes.

\section{Methodology}

To determine the most favorable $U$-values of building envelope elements, two-story residential buildings will be randomly generated using a hybrid evolution strategy [26 28] and their energy consumption evaluated using dynamic simulation [29, 30]. The construction system will have random $U$-values for the exterior opaque and transparent elements, ranging from 0.05 to 1.25 and 0.2 to $5.0 \mathrm{~W} \cdot \mathrm{m}^{-2} \cdot \mathrm{K}^{-1}$, respectively. The thermal inertia is kept the same in all buildings. The generated data will be divided by pairs of transparent/opaque $U$-values and the energy performance range will be determined. For each group, the performance will then be correlated with six geometry-based indexes (three related with building shape and the remaining with windows areas). Finally, the results will be analyzed and building design guidelines will be drawn and discussed.

\subsection{Generative design method}

The generative design method used to produce the alternative geometries, from the same user requirements and preferences, was the Evolutionary Program for the Space Allocation Problem (EPSAP) [26 28], which has been developed under the research project Ren4EEnIEQ [31]. The 
method works in a population-based two-stage procedure, where an Evolution Strategy (ES) has the mutation operator substituted by a Stochastic Hill Climbing (SHC) technique. The latter performs a set of random transformations, such as to move, rotate, stretch, reflect, and others to a single or a group of objects. These objects can be of different types, such as openings, spaces, stories, or clusters of spaces. The spaces can be rooms, stairs, or elevators that may serve one or more building stories. At the end of each generation, a selection mechanism picks the fittest individuals and the remaining population is randomly created for the next generation. When the process is complete, the energy performance is evaluated according to the selected energy consumption criteria [29, 30] using dynamic simulation (EnergyPlus version 8.8).

\subsection{Building specifications}

The building specifications correspond to the geometry restraints and requirements, construction system, internal gains and HVAC specifications, and climate locations, which are detailed in the following sections. The geometry specifications refer to the inputs used to generate alternative buildings for the same design program (list of rooms, minimum dimensions and areas, orientations, adjacencies, heights, number of openings and their dimensions, etc.). The construction system defines the building's constructive elements, their physical properties and the range of $U$-values that are randomly applied to each building geometry. The internal gains and HVAC specifications define the occupancy, equipment, lighting, and HVAC usage profiles that are specified for each thermal zone (i.e., inhabited spaces in the building), and are equal for all the generated buildings. The selected climate locations are characterized according to their geographic position; in this case, dispersed around the Mediterranean Sea, covering the coastal areas of the southern European, northern African, and middle east Asian countries.

Identical design program and usage profiles were considered for all generated buildings, in order to compare different locations using the same exact base building; as different specifications would not allow for a rigorous comparison. The influence of the culture, constructive, and dwelling context of each specific location on the building performance should also be studied in future works.

\subsubsection{Geometry constraints and requirements}

The building considered in this work is a two-story dwelling without boundaries or adjacent buildings, and with no specific orientation (i.e., the building orientation is randomly determined varying between $-45^{\circ}$ to $45^{\circ}$ North). The first floor $\left(L_{1}\right)$ includes a hall $\left(S_{1}\right)$, a living room $\left(S_{2}\right)$, a kitchen $\left(S_{3}\right)$, and a bathroom $\left(S_{4}\right)$. A staircase $\left(S_{5}\right)$ connects the first to the second floor $\left(L_{2}\right)$, which comprises a corridor $\left(S_{6}\right)$, a double bedroom $\left(S_{7}\right)$, a main bedroom $\left(S_{8}\right)$, a single bedroom $\left(S_{9}\right)$, and a bathroom $\left(S_{10}\right)$. The aimed height for each story is $2.70 \mathrm{~m}$. Table 1 summarizes the geometry and the topological requirements for each space. 
Table 1. Spaces geometry and topological specifications.

\begin{tabular}{cllllllccc}
\hline Space & $C^{s n}$ & $C^{s f}$ & $C^{r i}$ & $C^{s l}$ & $C^{s u}$ & $C^{s s}(\mathrm{~m})$ & $C^{s a}\left(\mathrm{~m}^{2}\right)$ & $C^{s s r}$ & $C^{s l r}$ \\
\hline$S_{1}$ & Hall & Circulation & Min & $L_{1}$ & $L_{1}$ & 2.70 & 10.0 & $\{2.0,3.0\}$ & $\{3.0,1.5\}$ \\
$S_{2}$ & Living room & Living & Max & $L_{1}$ & $L_{1}$ & 3.20 & - & 1.7 & 2.0 \\
$S_{3}$ & Kitchen & Service & Mid & $L_{1}$ & $L_{1}$ & 1.80 & - & 1.7 & 2.0 \\
$S_{4}$ & Bathroom & Service & Min & $L_{1}$ & $L_{1}$ & 2.20 & - & 1.7 & 2.0 \\
$S_{5}$ & Stair & Circulation & - & $L_{1}$ & $L_{2}$ & - & - & - & - \\
$S_{6}$ & Corridor & Circulation & None & $L_{2}$ & $L_{2}$ & 1.40 & 6.0 & $\{2.0,3.0\}$ & $\{3.0,1.5\}$ \\
$S_{7}$ & Double bedroom & Living & High & $L_{2}$ & $L_{2}$ & 2.70 & - & 1.7 & 2.0 \\
$S_{8}$ & Main bedroom & Living & High & $L_{2}$ & $L_{2}$ & 2.70 & - & 1.7 & 2.0 \\
$S_{9}$ & Single bedroom & Living & Mid & $L_{2}$ & $L_{2}$ & 2.70 & - & 1.7 & 2.0 \\
$S_{10}$ & Bathroom & Service & Min & $L_{2}$ & $L_{2}$ & 2.20 & - & 1.7 & 2.0 \\
\hline$C^{s n}-$ name, $C^{s f}-$ function, $C^{r i}-$ relative importance, $C^{s l}$ and $C^{s u}-$ served lower and upper stories, \\
$C^{s s}-$ minimum side dimension, $C^{s a}-$ minimum floor area, $C^{s s r}$ and $C^{s l r}-$ space smaller and larger side ratios \\
\hline \multicolumn{7}{c}{}
\end{tabular}

Each space may have exterior openings (windows and/or doors), depending on the generated building design. For example, the living room $\left(S_{2}\right)$ has an opening $\left(O e_{2}\right)$ of type window $\left(C^{o e t}\right)$, with $2.80 \mathrm{~m}$ width $\left(C^{\text {oew }}\right), 2.0 \mathrm{~m}$ height $\left(C^{\text {oeh }}\right)$, and elevated $1.0 \mathrm{~m}$ from the floor $\left(C^{\text {oev }}\right)$. Table 2 lists all exterior openings in the design program per space $\left(C^{o s}\right)$.

Table 2. Exterior openings geometry specifications.

\begin{tabular}{lclccc}
\hline$C^{\text {os }}$ & Opening & $C^{\text {oet }}$ & $C^{\text {oew }}(\mathrm{m})$ & $C^{\text {oeh }}(\mathrm{m})$ & $C^{\text {oev }}(\mathrm{m})$ \\
\hline$S_{1}$ & $O e_{1}$ & Door & 1.00 & 2.00 & 0 \\
$S_{2}$ & $O e_{2}$ & Window & 2.80 & 2.00 & 0 \\
$S_{3}$ & $O e_{3}$ & Window & 1.20 & 1.00 & 1.00 \\
$S_{4}$ & $O e_{4}$ & Window & 0.60 & 0.60 & 1.40 \\
$S_{5}$ & $O e_{5}$ & Window & 0.80 & 1.40 & 0.80 \\
$S_{6}$ & - & - & - & - & - \\
$S_{7}$ & $O e_{6}$ & Window & 1.80 & 1.00 & 1.00 \\
$S_{8}$ & $O e_{7}$ & Window & 1.80 & 1.00 & 1.00 \\
$S_{9}$ & $O e_{8}$ & Window & 1.20 & 1.00 & 1.00 \\
$S_{10}$ & - & - & - & - & - \\
\hline$C^{\text {os }}-$ space, $C^{\text {oet }}-$ opening type, $C^{\text {oew }}-$ minimum width, \\
$C^{\text {oeh }}-$ minimum height, $C^{\text {oev }}-$ vertical position \\
\hline \multicolumn{5}{c}{} \\
\hline \multicolumn{5}{c}{}
\end{tabular}

The spaces may also have adjacent or connectivity requirements - Table 3 . For instance, the interior opening $\left(O i_{2}\right)$ of type door $\left(C^{\text {oit }}\right)$, with $0.9 \mathrm{~m}$ width $\left(C^{\text {oiw }}\right), 2.0 \mathrm{~m}$ height $\left(C^{\text {oih }}\right)$, and $0 \mathrm{~m}$ of elevation from the floor $\left(C^{\text {oiv }}\right)$, connects space $S_{1}\left(C^{o i a}\right)$ to space $S_{3}\left(C^{o i b}\right)$. Otherwise, when there is only adjacency between spaces but no opening, a $0 \mathrm{~m}$ wide opening is considered (e.g., $O i_{5}$ ).

Table 3. Interior openings geometry and topologic specifications.

\begin{tabular}{clccccc}
\hline Opening & $C^{\text {oit }}$ & $C^{\text {oia }}$ & $C^{\text {oib }}$ & $C^{\text {oiw }}(\mathrm{m})$ & $C^{\text {oih }}(\mathrm{m})$ & $C^{\text {oiv }}(\mathrm{m})$ \\
\hline$O i_{1}$ & Door & $S_{1}$ & $S_{2}$ & 1.40 & 2.00 & 0 \\
$O i_{2}$ & Door & $S_{1}$ & $S_{3}$ & 0.90 & 2.00 & 0 \\
$O i_{3}$ & Door & $S_{1}$ & $S_{4}$ & 0.90 & 2.00 & 0 \\
$O i_{4}$ & Door & $S_{5}$ & $S_{1}$ & 0.90 & 2.00 & 0 \\
$O i_{5}$ & Adjacency & $S_{2}$ & $S_{3}$ & 0 & - & - \\
$O i_{6}$ & Door & $S_{5}$ & $S_{6}$ & 0.90 & 2.00 & 0 \\
$O i_{7}$ & Door & $S_{6}$ & $S_{7}$ & 0.90 & 2.00 & 0 \\
$O i_{8}$ & Door & $S_{6}$ & $S_{8}$ & 0.90 & 2.00 & 0 \\
$O i_{9}$ & Door & $S_{6}$ & $S_{9}$ & 0.90 & 2.00 & 0 \\
$O i_{10}$ & Door & $S_{6}$ & $S_{10}$ & 0.90 & 2.00 & 0 \\
\hline$C^{\text {oit }}-$ type, $C^{\text {oia }}-$ opening's space, $C^{\text {oib }}-$ destination space, \\
$C^{\text {oiw }}-$ minimum width, $C^{\text {oih }}-$ minimum height, $C^{\text {oiv }- \text { vertical position }}$ \\
\hline \multicolumn{7}{c}{}
\end{tabular}




\subsubsection{Construction system}

The building has strong inertia with current material properties. Its construction elements and respective properties are presented in Table 4. The thermal mass of all exterior opaque elements apart from doors (exterior walls, roofs, and suspended slabs) is considered to be equivalent to that of an interior slab (see Table 4), while the $U$-value is randomly changed throughout the dynamic simulations $-0.05 \mathrm{~W} \cdot \mathrm{m}^{-2} \cdot \mathrm{K}^{-1}$ to $1.25 \mathrm{~W} \cdot \mathrm{m}^{-2} \cdot \mathrm{K}^{-1}$, in steps of $0.05 \mathrm{~W} \cdot \mathrm{m}^{-2} \cdot \mathrm{K}^{-1}$. The same $U$-values are also applied to the exterior doors. Regarding the exterior transparent elements, a constant solar heat gain coefficient (SHGC) of 0.6 is considered and the variable $U$-values are proportionally paired with those of the opaque elements $-0.2 \mathrm{~W} \cdot \mathrm{m}^{-2} \cdot \mathrm{K}^{-1}$ to $5.0 \mathrm{~W} \cdot \mathrm{m}^{-2} \cdot \mathrm{K}^{-1}$, in steps of $0.2 \mathrm{~W} \cdot \mathrm{m}^{-2} \cdot \mathrm{K}^{-1}$.

Table 4. Building's construction elements.

\begin{tabular}{|c|c|c|c|c|c|c|c|}
\hline Element & Layer & Thickness (m) & $k\left(\mathrm{~W} \cdot \mathrm{m}^{-1} \cdot \mathrm{K}^{-1}\right)$ & $\rho\left(\mathrm{kg} \cdot \mathrm{m}^{-3}\right)$ & $c_{p}\left(\mathrm{~J} \cdot \mathrm{kg}^{-1} \cdot \mathrm{K}^{-1}\right)$ & $U\left(\mathrm{~W} \cdot \mathrm{m}^{-2} \cdot \mathrm{K}^{-1}\right)$ & SHGC \\
\hline \multirow{3}{*}{ Interior wall } & Finishing layer & 0.02 & 0.22 & 950 & 840 & \multirow{3}{*}{4.499} & - \\
\hline & Structural layer & 0.07 & 1.73 & 2243 & 836.8 & & \\
\hline & Finishing layer & 0.02 & 0.22 & 950 & 840 & & \\
\hline \multirow{4}{*}{ Interior slab } & Finishing layer & 0.02 & 0.22 & 950 & 840 & \multirow{4}{*}{2.841} & - \\
\hline & Structural layer & 0.2 & 1.73 & 2245.6 & 836.8 & & \\
\hline & Regulation layer & 0.01 & 0.22 & 950 & 840 & & \\
\hline & Finishing layer & 0.02 & 0.2 & 825 & 2385 & & \\
\hline \multirow{5}{*}{ Ground floor } & Structural layer & 0.2 & 1.73 & 2245.6 & 836.8 & \multirow{5}{*}{0.437} & - \\
\hline & Insulation layer & 0.08 & 0.04 & 32.1 & 836.8 & & \\
\hline & Filling layer & 0.02 & 0.8 & 1600 & 840 & & \\
\hline & Regulation layer & 0.01 & 0.22 & 950 & 840 & & \\
\hline & Finishing layer & 0.02 & 0.2 & 825 & 2385 & & \\
\hline \multirow{3}{*}{ Interior door } & Finishing layer & 0.005 & 0.2 & 825 & 2385 & \multirow{3}{*}{2.009} & - \\
\hline & Structural layer & 0.03 & 0.067 & 430 & 1260 & & \\
\hline & Finishing layer & 0.005 & 0.2 & 825 & 2385 & & \\
\hline Exterior window & - & - & - & - & - & $\operatorname{RAND}\{0.2, \cdots, 5.0\}$ & 0.6 \\
\hline Envelope elements & \multicolumn{5}{|c|}{ Internal mass equivalent to Interior slab } & $\operatorname{RAND}\{0.05, \cdots, 1.25\}$ & - \\
\hline
\end{tabular}

\subsubsection{Occupancy, equipment, lighting, and HVAC specifications}

The occupancy patterns and the operation schedules of equipment and lighting are based on the building typology. The building is considered as a single-family house occupied by five people. The occupancy patterns in the different spaces throughout the day is depicted in Fig. 1. The internal heat gains due to occupancy are also related to the maximum number of people per zone and the respective activity level, which are presented in Table 5 .

The internal gains due to electric lights are defined by the maximum design lighting level for each zone type, presented in Table 6, and the correspondent usage schedules, depicted in Fig. 2 . The schedules are based on the building zone typology, occupancy, and window shading. The shadings are assumed to be PVC roller shutters that cover all the windows during night-time. In addition, daylighting controls, which determine how much the electric lighting can be dimmed, are considered for all zones with exterior windows - a $300 \mathrm{~lx}$ daylight illuminance setpoint is considered 


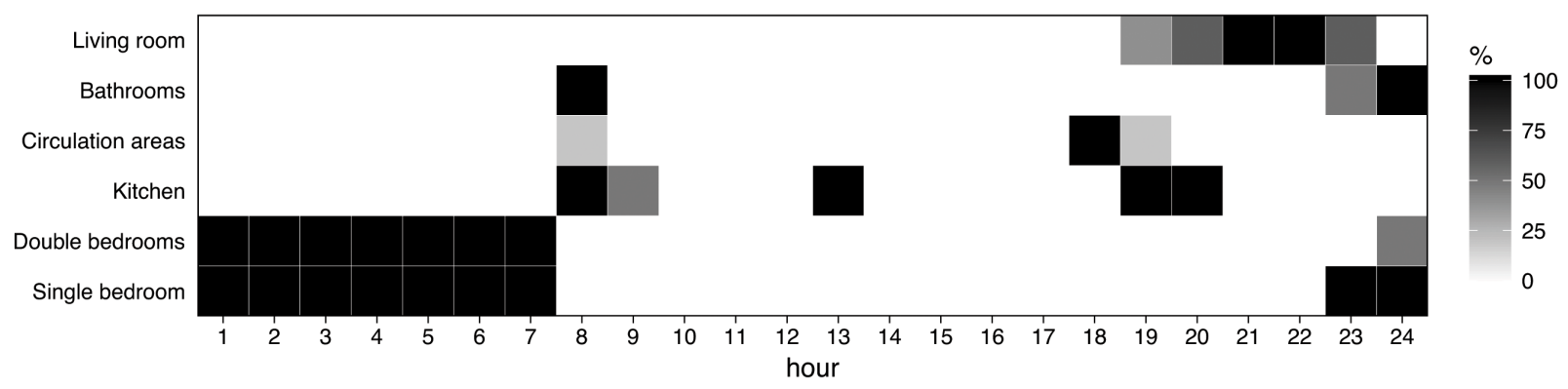

Fig. 1. General occupancy pattern in the building zones.

Table 5. Maximum number of people per zone and correspondent activity levels.

\begin{tabular}{lcc}
\hline Zone type & Max number of people ${ }^{a}$ & ${\text { Activity level }\left(\mathrm{W} \cdot \text { person }^{-1}\right)}^{\text {Living room }}$ \\
Bathrooms & 5 & 110 \\
Circulation areas & 1 & 207 \\
Kitchen & 1 & 190 \\
Double/Main bedroom & 2 & 190 \\
Single bedroom & 2 & 72 \\
\hline${ }^{a}$ - Regarding the building inhabitants accessing each zone, and not necessarily the number \\
of occupants simultaneously in the zone. The occupant's distribution is defined together \\
with the proper occupancy schedules.
\end{tabular}

for the lights switching off. This dimming control should be seen here not as much as artificial lighting, but as a "simulation procedure" that allows to adjust the lighting values according to available daylight in each latitude, since the electric lighting profiles are identical in all locations.

Table 6. Maximum design lighting levels for each zone type.

\begin{tabular}{lc}
\hline Zone type & Design lighting level $\left(\mathrm{W} \cdot \mathrm{m}^{-2}\right)$ \\
\hline Living room/Bedrooms & 7.5 \\
Bathrooms & 7.5 \\
Circulation areas & 3.2 \\
Kitchen & 5 \\
\hline
\end{tabular}

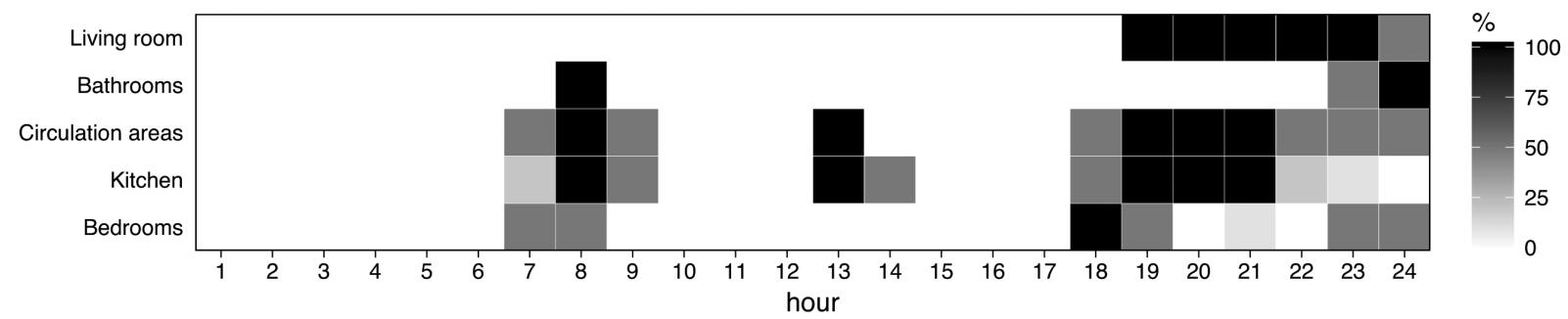

Fig. 2. Electric light schedule in each zone.

The internal heat gains due to electric equipment depend on the maximum design wattage levels of the equipment in each zone (Table 7), which are based on the building zone typology and the appliances typically found in each zone, and the corresponding usage schedules (Fig. 3). These schedules are based on the building zone typology and occupancy.

Regarding ventilation and infiltration specifications, a 0.6 air changes per hour (ACH) exhaust rate is considered for the kitchen and the bathrooms, with a flow rate profile equivalent to the 
Table 7. Total heat gains from electric equipment in each zone.

\begin{tabular}{lc}
\hline Zone type & Design level $(\mathrm{W})$ \\
\hline Living room & 350 \\
Bathrooms & 100 \\
Circulation areas & 20 \\
Kitchen & 1440 \\
Bedrooms & 250 \\
\hline
\end{tabular}

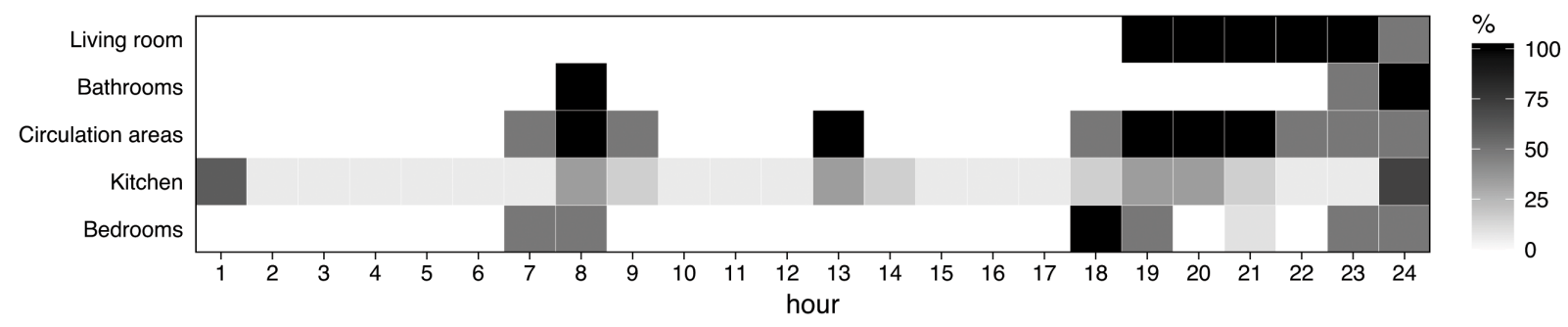

Fig. 3. Electric equipment schedules in each zone.

occupation schedules defined for these two zones (Fig. 1), while 0.2 ACH and 0.1 ACH are considered for the outdoor air infiltration into zones with and without exterior openings, respectively.

The living room and the bedrooms are the only spaces in the building where heating and cooling are considered. For this purpose, the ideal loads air system model of EnergyPlus is used, which allows to assess the performance of the building without modeling a full HVAC system, meeting all the load requirements 32 . The air temperature thermostat setpoints assumed for cooling and heating are $25.0^{\circ} \mathrm{C}$ and $20.0^{\circ} \mathrm{C}$, respectively, for all the case studies. A $50 \%$ dehumidification setpoint and a 0.7 cooling sensible heat ratio were also considered. The corresponding heating/cooling availability schedules for each zone are equivalent to the occupation schedules defined for the respective zones (Fig. 1).

\subsubsection{Mediterranean locations}

For this study, sixteen locations were selected in the Mediterranean region - Venice (Italy, ITA), Marseille (France, FRA), Podgorica (Montenegro, MNE), Istanbul (Turkey, TUR), Naples (ITA), Valencia (Spain, ESP), Izmir (TUR), Athens (Greece, GRC), Tunis (Tunisia, TUN), Algiers (Algeria, DZA), Malaga (ESP), Larnaca (Cyprus, CYP), Casablanca (Morocco, MAR), Tripoli (Libya, LBY), Tel Aviv (Israel, ISR), and Alexandria (Egypt, EGY). The weather data from these locations were downloaded from the EnergyPlus website [33]. Fig. 4 depicts the map with the locations of the selected cities and Table 8 summarizes the corresponding climates (type and description), according to the Köppen-Geiger World Map climate classification [34, and the geographic references (country, latitude, longitude, and altitude). In Appendix A, the annual evolution of dry bulb temperature, solar radiation and relative humidity are presented for the sixteen locations. 


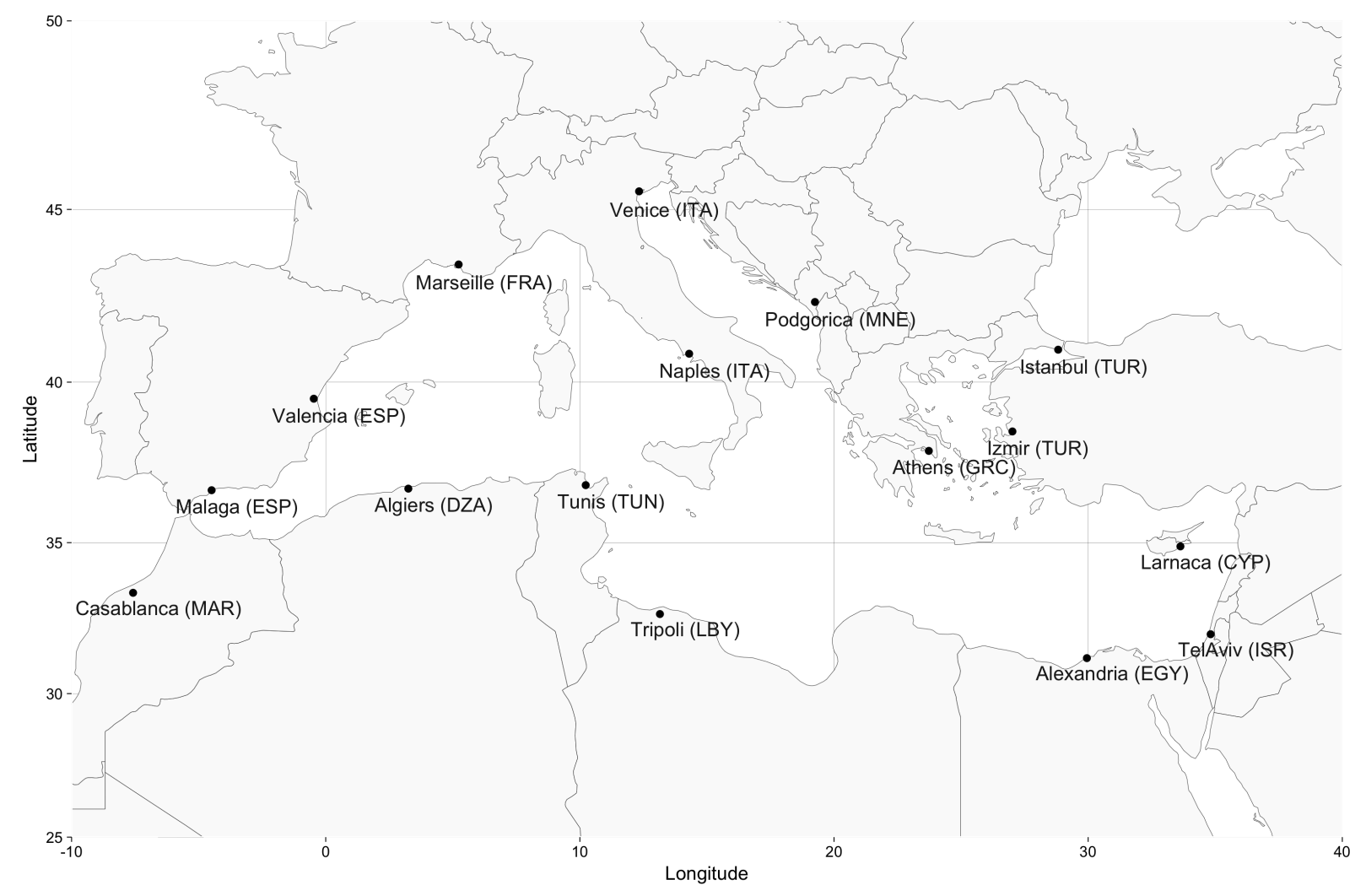

Fig. 4. Map of the studied locations in the Mediterranean.

Table 8. Climate classification of each location.

\begin{tabular}{rlrrlll}
\hline & & Location & & & Climate \\
City & Country & Latitude & Longitude & Altitude (m) & Type & Climate description \\
\hline Venice & Italy (ITA) & $45.50 \mathrm{~N}$ & $12.33 \mathrm{E}$ & 6 & Cfa & Humid subtropical (mild with no dry season, hot summer) \\
Marseille & France (FRA) & $43.45 \mathrm{~N}$ & $5.23 \mathrm{E}$ & 36 & Cfa & Humid subtropical (mild with no dry season, hot summer) \\
Podgorica & Montenegro (MNE) & $42.37 \mathrm{~N}$ & $19.25 \mathrm{E}$ & 33 & Cfa & Humid subtropical (mild with no dry season, hot summer) \\
Istanbul & Turkey (TUR) & $40.97 \mathrm{~N}$ & $28.82 \mathrm{E}$ & 37 & Cfa & Humid subtropical (mild with no dry season, hot summer) \\
Naples & Italy (ITA) & $40.85 \mathrm{~N}$ & $14.30 \mathrm{E}$ & 72 & Cfa & Humid subtropical (mild with no dry season, hot summer) \\
Valencia & Spain (ESP) & $39.50 \mathrm{~N}$ & $0.47 \mathrm{~W}$ & 62 & Cfa & Humid subtropical (mild with no dry season, hot summer) \\
Izmir & Turkey (TUR) & $38.50 \mathrm{~N}$ & $27.02 \mathrm{E}$ & 5 & Cfa & Humid subtropical (mild with no dry season, hot summer) \\
Athens & Greece (GRC) & $37.90 \mathrm{~N}$ & $23.73 \mathrm{E}$ & 15 & Cfa & Humid subtropical (mild with no dry season, hot summer) \\
Tunis & Tunisia (TUN) & $36.83 \mathrm{~N}$ & $10.23 \mathrm{E}$ & 4 & Cfa & Humid subtropical (mild with no dry season, hot summer) \\
Algiers & Algeria (DZA) & $36.72 \mathrm{~N}$ & $3.25 \mathrm{E}$ & 25 & Cfa & Humid subtropical (mild with no dry season, hot summer) \\
Malaga & Spain (ESP) & $36.67 \mathrm{~N}$ & $4.49 \mathrm{~W}$ & 7 & Csa & Mediterranean climate (dry hot summer, mild winter) \\
Larnaca & Cyprus (CYP) & $34.88 \mathrm{~N}$ & $33.63 \mathrm{E}$ & 2 & Cfa & Humid subtropical (mild with no dry season, hot summer) \\
Casablanca & Morocco (MAR) & $33.37 \mathrm{~N}$ & $7.58 \mathrm{~W}$ & 206 & Cfa & Humid subtropical (mild with no dry season, hot summer) \\
Tripoli & Libya (LBY) & $32.67 \mathrm{~N}$ & $13.15 \mathrm{E}$ & 81 & BSh & Hot subtropical steppe \\
Tel Aviv & Israel (ISR) & $32.00 \mathrm{~N}$ & $34.82 \mathrm{E}$ & 35 & Cfa & Humid subtropical (mild with no dry season, hot summer) \\
Alexandria & Egypt (EGY) & $31.20 \mathrm{~N}$ & $29.95 \mathrm{E}$ & 7 & Cfa & Humid subtropical (mild with no dry season, hot summer) \\
\hline
\end{tabular}

\subsection{Synthetic dataset}

The synthetic dataset was created by running the EPSAP algorithm 500 times for each location, with 24 buildings per run produced, totalizing 192000 dwellings. These were generated randomly within the defined specifications and with random exterior construction elements thermal transmittance (roof, suspended floors, exterior wall, and windows), as presented in previous subsection 2.2 . For each run, the geometry data (number of stories, spaces, openings, elements surface areas, volumes, and other geometric information), construction data (transparent and opaque elements 
physical properties), and performance data (electric energy consumption, water consumption, thermal discomfort, and thermal energy production) were stored. The dataset is divided according to each location and it is publicly available online (see ref. [35]). Fig. 5 depicts some building geometry examples generated by the EPSAP algorithm for the specifications described in section 2 . Regarding the simulation procedure, EnergyPlus performs a dynamic annual simulation for each building in the dataset, thus managing both of the day/night and seasonal dynamic behaviors, considering the specific weather data for each case.
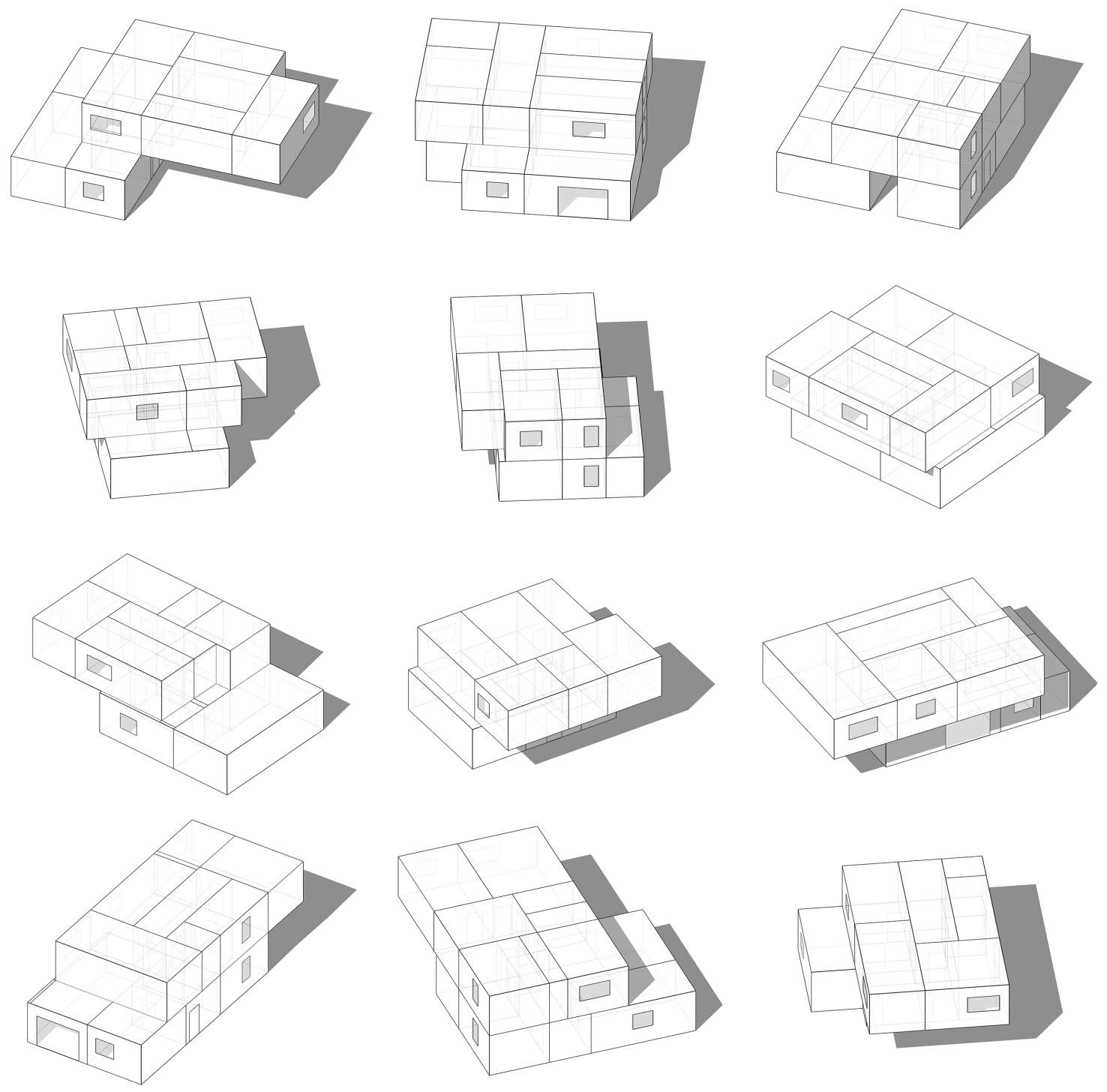

Fig. 5. Twelve examples of two-story buildings generated by EPSAP algorithm.

\subsection{Statistical analysis}

To perform the statistical analysis, the 192000 buildings were split into groups by location and by their opaque and transparent elements $U$-values, and each group was divided in quartiles according to the total energy demand for air-conditioning, cooling and heating energy consumption 
in the form of whisker diagrams (boxplots). Additionally, for each group, the energy consumption was correlated with six geometry-based indexes - building volume, two building compactness indexes, and three window-based indexes - to study the impact of variable thermal transmittance of the building envelope elements. The variation of the building volume $(V)$ allows to understand in which way the building's size influences its energy performance, as all generated buildings will have the same design program and usage profiles (same internal gains and HVAC specifications). The shape coefficient $\left(C_{f}=S / V\left[\mathrm{~m}^{-1}\right]\right)$ [36] represents the relation between the envelope surface area $(S)$ and the building volume $(V)$. However, it depends on the building size, thus different results can be obtained for the same building shape. On the other hand, the relative compactness index $\left(R C=6 V^{2 / 3} / S\right)$ provides a comparison to a reference building of the same volume, thus overcoming the shape coefficient limitation. The window-related indexes are based on the window areas $\left(S_{\text {win }}\right)$ and their relation with the building floor areas $\left(W F R=S_{w i n} / S_{f l o o r}\right)$, exterior wall areas $\left(W W R=S_{\text {win }} / S_{\text {wall }}\right)$, and the surface areas in contact with the outdoor ambient $\left(W S R=S_{\text {win }} / S\right)$. Although $W F R$ and $W W R$ are the most commonly used window-based indexes, $W S R$ captures better the impact of the exterior opaque elements and their relation with the window areas [14]. Therefore, the $W S R$ for each cardinal orientation was also analyzed $-W S R-N$, $W S R-E, W S R-S$, and $W S R-W$ for North, East, South, and West orientations, respectively.

\section{Results}

Figs. 6 and 7 present the total, cooling, and heating energy consumption for air-conditioning boxplots (in $\mathrm{kW} \cdot \mathrm{h}$ ) for each $U$-value group per location. They also depict the distribution of buildings per group. The locations are sorted descending by latitude from top to bottom rows and the horizontal axis corresponds to each $U$-value group, ranging from $0.2 \mathrm{~W} \cdot \mathrm{m}^{-2} \cdot \mathrm{K}^{-1}$ to $5.0 \mathrm{~W} \cdot \mathrm{m}^{-2} \cdot \mathrm{K}^{-1}$, in steps of $0.2 \mathrm{~W} \cdot \mathrm{m}^{-2} \cdot \mathrm{K}^{-1}$, for transparent elements, and from $0.05 \mathrm{~W} \cdot \mathrm{m}^{-2} \cdot \mathrm{K}^{-1}$ to $1.25 \mathrm{~W} \cdot \mathrm{m}^{-2} \cdot \mathrm{K}^{-1}$, in steps of $0.05 \mathrm{~W} \cdot \mathrm{m}^{-2} \cdot \mathrm{K}^{-1}$, for opaque elements. In northern locations - e.g., Venice (ITA), Podgorica (MNE), Istanbul (TUR) - there is a tendency in the amplitude of energy consumption (i.e., the difference between the maximum and minimum energy consumption) to decrease as the $U$-values reduce. This happens due to the smaller contribution from the heating demands and a relatively slow growth of the cooling demands, as the $U$-values decrease. On the other hand, in intermediate latitudes - e.g., Valencia (ESP), Izmir (TUR), Athens (GRC) - the cooling demands start to have a bigger contribution to the total energy, for smaller $U$-values. Therefore, there is also a tendency in the amplitude of energy consumption to decrease as the $U$-values reduce, which is, however, inverted for small $U$-values. Finally, in locations where the climate is even warmer, for smaller $U$-values the cooling energy demand increases greatly, becoming by far the major energy consumption factor. As this happens, the energy performance worsens and 
the amplitude of energy consumption increases. For the remaining $U$-values on the right side of the scale, the amplitude of energy consumption remains practically constant. This is especially noticeable in lower latitudes - e.g., Casablanca (MAR), Tel Aviv (ISR), Alexandria (EGY) -, where the heating energy demands are much smaller. In general, the most adequate $U$-values (the minimum amplitude of energy consumption and the lowest energy consumption) tend to move further into the right side of the scale for lower latitudes, as represented by the blue vertical line in Figs. 6 and 7

Figs. 8 to 11 show, in the left graphic, the coefficient of determination for the correlation between the geometry-based indexes $\left(\mathrm{V}\right.$ - building volume, $R C$ - relative compactness, $C_{f}-$ shape coefficient, $W F R$ - window-to-floor ratio, $W W R$ - window-to-wall ratio, $W S R$ - windowto-exterior surface ratio, and WSR for orientation North, East, South, and West) and the $U$-value group for each climate region. In this context, for a group of buildings with the same $U$-value, this coefficient represents the relation between the buildings' energy performance and the geometric variable. In the right graphic, it is depicted for each sample pair index-group the calculated probability that did not reject the null hypothesis $\left(\mathrm{H}_{0}\right)$ for a threshold of $p$-value $\leq 0.01$. The green cells represent negative correlation (i.e., the increase of such index decreases the energy consumption) and red cells depict positive correlation - the increase of both the index and energy consumption. The correlation scale (coefficient of determination, $\mathrm{R}^{2}$ ) was considered having the intervals $[0,0.2[$ for very weak, $[0.2,0.4[$ for weak, $[0.4,0.6[$ for moderate, $[0.6,0.8[$ for strong, and $[0.8,1]$ for very strong.

As depicted in Figs. 8 to 11 , the building volume $(V)$ has moderate positive correlation with energy consumption for higher $U$-values. In other words, bigger buildings require more energy to maintain the indoor environment within the thermal comfort limits. As the $U$-values decrease, the correlation weakens, reaching none for all locations. And with exception of the most southern locations, the building volume even becomes negatively week correlated for very low $U$-values, thus the bigger the building the less energy it consumes.

Relatively to shape indexes, shape coefficient $\left(C_{f}\right)$ does not present any kind of correlation for any of the $U$-values, in any of the locations. This may be justified with the volume variation of the generated buildings. When considering the relative compactness $(R C)$, the correlation goes from weak negative to none or very weak for smaller $U$-values, thus meaning that the building compactness has some influence in the energy consumption - compact buildings decrease energy consumption for higher $U$-values. However, in southern countries, for low $U$-values, the tendency for the $R C$ is to invert its correlation, presenting very weak positive correlation; meaning that compact buildings increase energy consumption. 

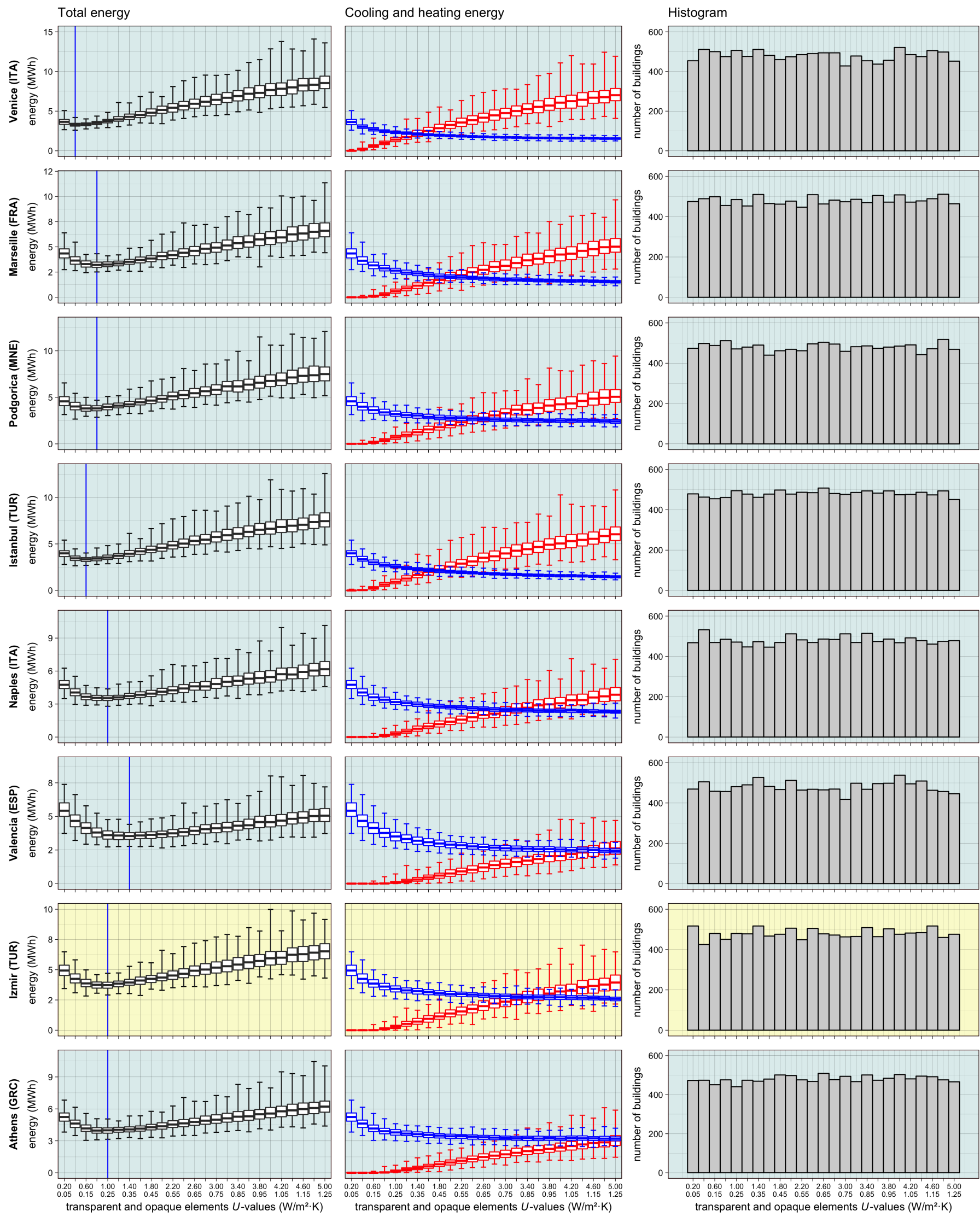

Fig. 6. Total, cooling, and heating energy consumption boxplots and histograms per $U$-value group per climate location (part $1 / 2)$. Blue boxplots represent cooling energy and red boxplots the heating energy. The blue vertical line represents the most adequate $U$-value (lowest average of total energy consumption). The light blue background indicates the locations in Europe, light yellow in Asia, and light red in Africa continent. 

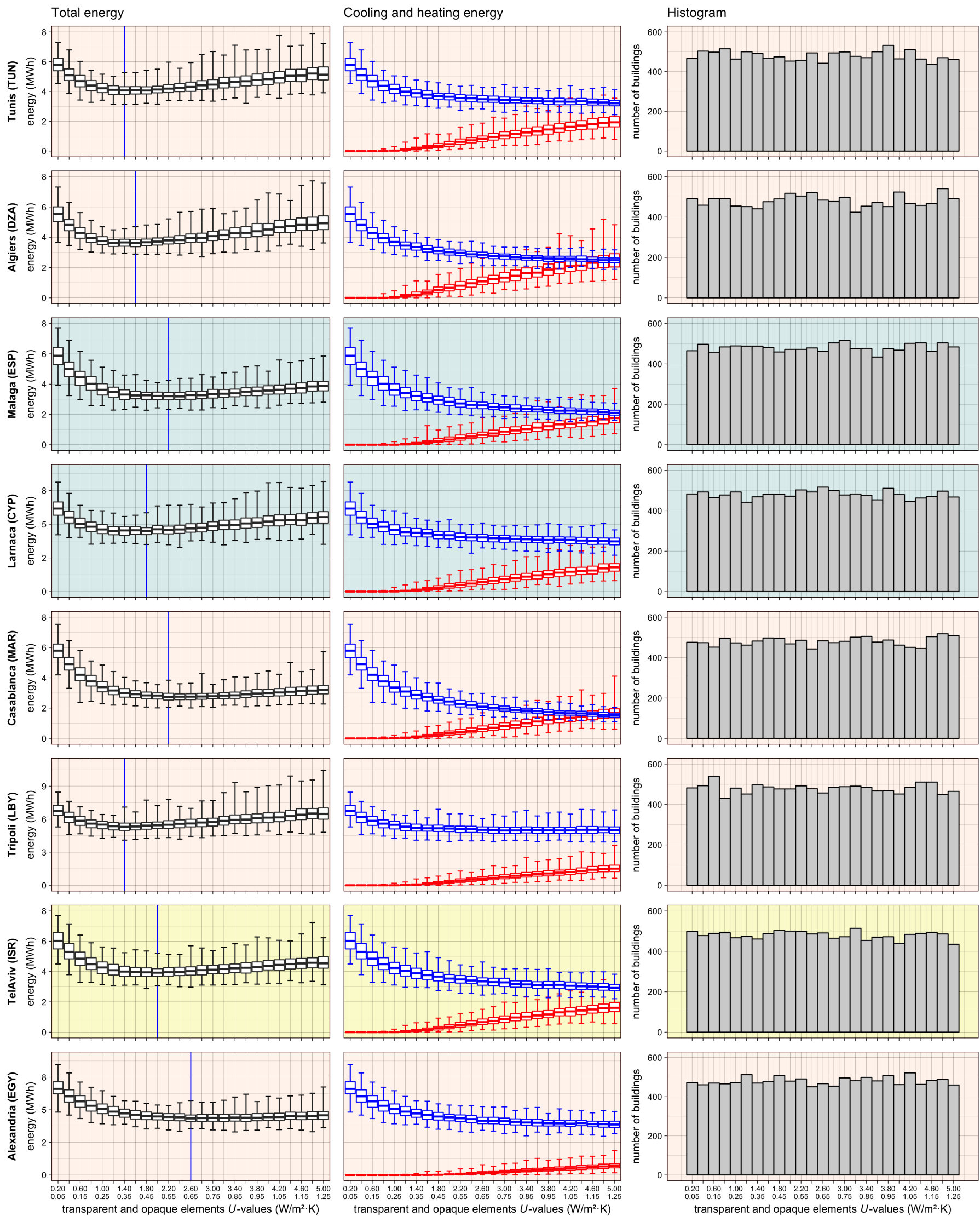

Fig. 7. Total, cooling, and heating energy consumption boxplots and histograms per $U$-value group per climate location (part $2 / 2$ ). Blue boxplots represent cooling energy and red boxplots the heating energy. The blue vertical line represents the most adequate $U$-value (lowest average of total energy consumption). The light blue background indicates the locations in Europe, light yellow in Asia, and light red in Africa continent. 


\section{Correlation}

Coefficient of determination

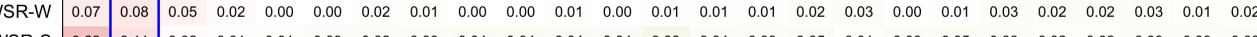
\begin{tabular}{l|l|llllllllllllllllllllllll} 
WSR-S & 0.23 & 0.11 & 0.02 & 0.01 & 0.01 & 0.03 & 0.02 & 0.03 & 0.04 & 0.04 & 0.04 & 0.04 & 0.08 & 0.04 & 0.03 & 0.05 & 0.01 & 0.03 & 0.05 & 0.03 & 0.02 & 0.02 & 0.03 & 0.03 & 0.03
\end{tabular}

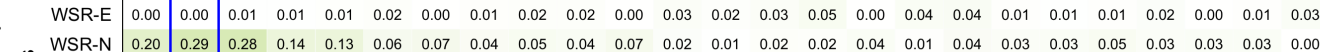

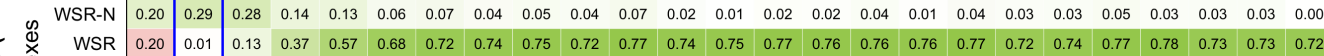

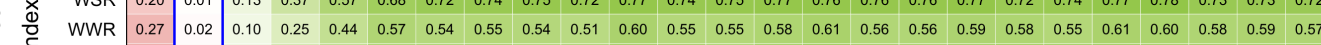
$\begin{array}{llllllllllllllllllllllllll}\text { WFR } & 0.31 & 0.02 & 0.11 & 0.31 & 0.46 & 0.58 & 0.57 & 0.59 & 0.55 & 0.56 & 0.64 & 0.62 & 0.57 & 0.63 & 0.67 & 0.62 & 0.60 & 0.63 & 0.64 & 0.63 & 0.65 & 0.63 & 0.64 & 0.63 & 0.65\end{array}$

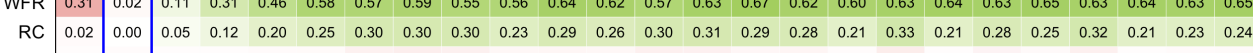

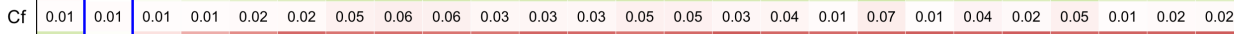
$\begin{array}{llllllllllllllllllllllllll} & 0.30 & 0.02 & 0.11 & 0.31 & 0.44 & 0.60 & 0.55 & 0.58 & 0.55 & 0.54 & 0.62 & 0.60 & 0.55 & 0.59 & 0.66 & 0.60 & 0.59 & 0.62 & 0.65 & 0.61 & 0.64 & 0.61 & 0.63 & 0.63 & 0.65\end{array}$

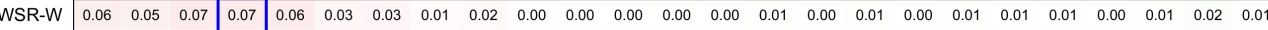
$\begin{array}{llllllllllllllllllllllllll}\text { WSR-S } & 0.25 & 0.26 & 0.16 & 0.07 & 0.00 & 0.00 & 0.06 & 0.06 & 0.09 & 0.08 & 0.07 & 0.09 & 0.06 & 0.05 & 0.02 & 0.05 & 0.04 & 0.08 & 0.05 & 0.06 & 0.06 & 0.06 & 0.04 & 0.02 & 0.03\end{array}$ \begin{tabular}{l|llllllllllllllllllllllllll} 
WSR-E & 0.00 & 0.00 & 0.00 & 0.00 & 0.00 & 0.00 & 0.00 & 0.00 & 0.01 & 0.01 & 0.00 & 0.01 & 0.01 & 0.02 & 0.02 & 0.03 & 0.01 & 0.00 & 0.03 & 0.03 & 0.02 & 0.00 & 0.02 & 0.00 & 0.03
\end{tabular} WSR-N $\begin{array}{lllllllllllllllllllllllllllllll}0.22 & 0.25 & 0.32 & 0.33 & 0.23 & 0.30 & 0.15 & 0.11 & 0.08 & 0.08 & 0.05 & 0.04 & 0.03 & 0.05 & 0.04 & 0.01 & 0.04 & 0.03 & 0.01 & 0.01 & 0.02 & 0.06 & 0.03 & 0.05 & 0.03\end{array}$

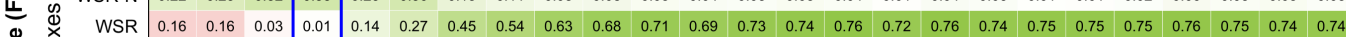
\begin{tabular}{lllllllllllllllllllllll}
\hline & 0.75
\end{tabular}

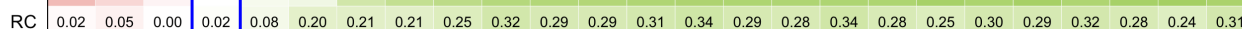

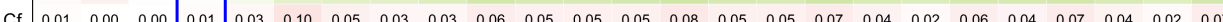

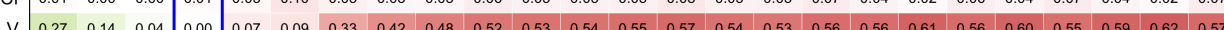

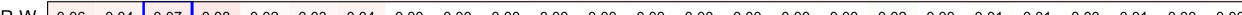
\begin{tabular}{ll|lllllll} 
& 0.04 & 0.07 & 0.00
\end{tabular}

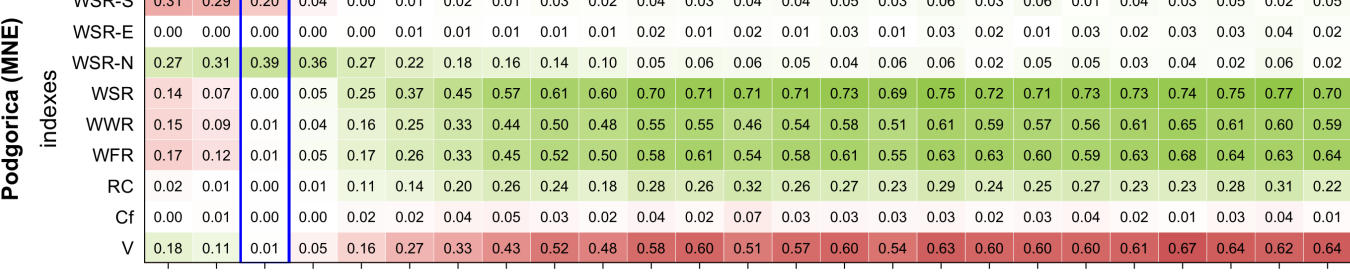
$\begin{array}{llllllllllllllllllllllllll}\text { WSR-W } & 0.06 & 0.07 & 0.07 & 0.07 & 0.04 & 0.01 & 0.00 & 0.01 & 0.00 & 0.00 & 0.00 & 0.00 & 0.00 & 0.01 & 0.01 & 0.00 & 0.01 & 0.01 & 0.01 & 0.00 & 0.00 & 0.01 & 0.01 & 0.01 & 0.01\end{array}$ $\begin{array}{llllllllllllllllllllllllll}\text { WSR-S } & 0.19 & 0.18 & 0.06 & 0.00 & 0.01 & 0.00 & 0.01 & 0.02 & 0.01 & 0.02 & 0.02 & 0.02 & 0.00 & 0.01 & 0.04 & 0.03 & 0.03 & 0.02 & 0.03 & 0.05 & 0.01 & 0.01 & 0.02 & 0.04 & 0.02\end{array}$

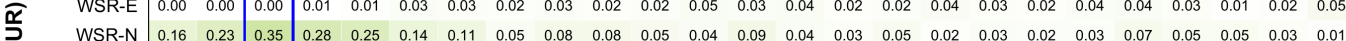

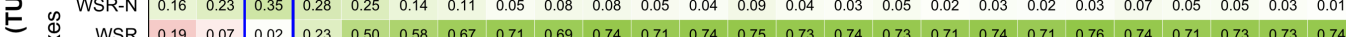

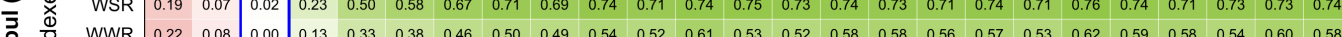

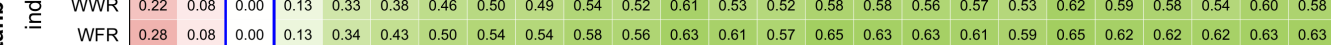
$\begin{array}{llllllllllllllllllllllllll}\text { RC } & 0.26 & 0.08 & 0.00 & 0.13 & 0.34 & 0.43 & 0.50 & 0.54 & 0.54 & 0.58 & 0.56 & 0.63 & 0.61 & 0.57 & 0.65 & 0.63 & 0.63 & 0.61 & 0.59 & 0.65 & 0.62 & 0.62 & 0.62 & 0.63 & 0.63\end{array}$

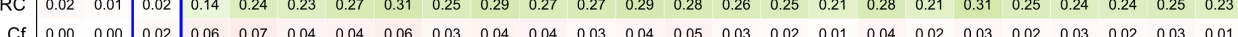

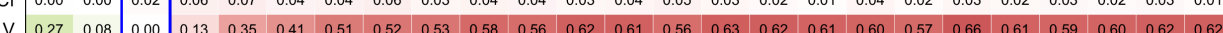

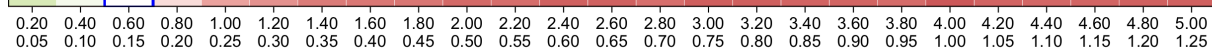
transparent and opaque elements $U$-values $\left(\mathrm{W} / \mathrm{m}^{2} \cdot \mathrm{K}\right)$

\section{Calculated probability} $p$-value

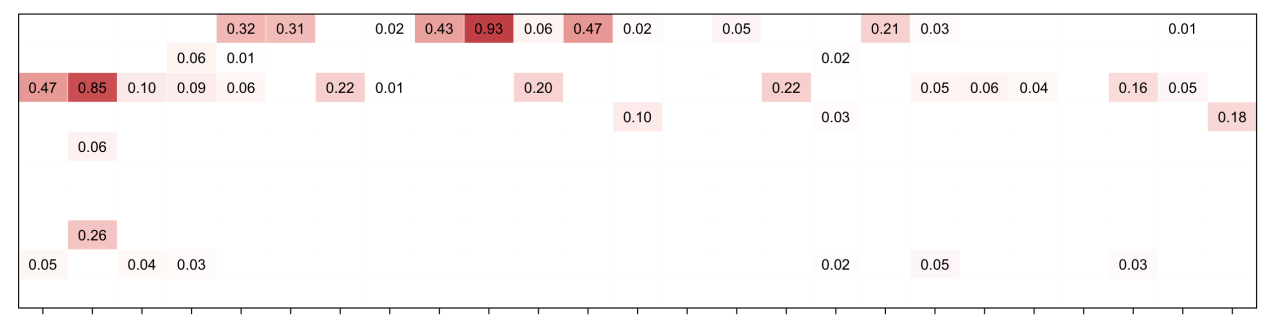

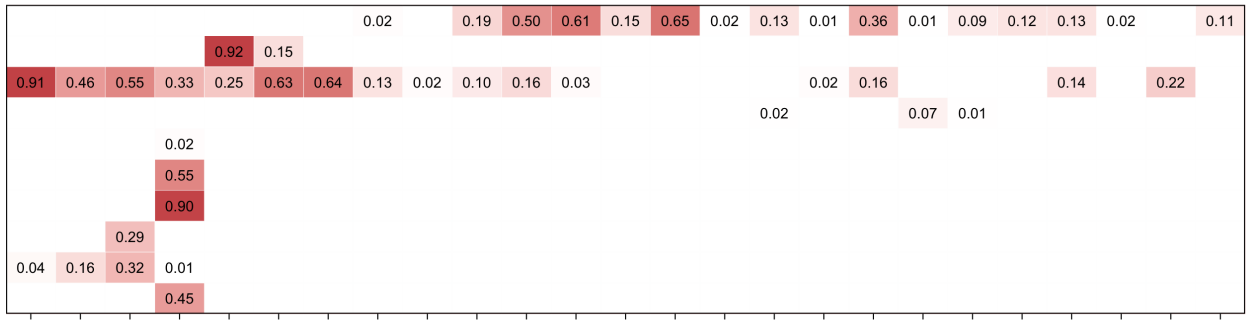

\begin{tabular}{|c|c|c|c|c|c|c|c|c|c|c|c|c|c|c|}
\hline & & & & 0.34 & 0.22 & $0.26 \quad 0.69$ & $\begin{array}{ll}0.14 & 0.49\end{array}$ & $\begin{array}{ll}0.61 & 0.63\end{array}$ & $0.14 \quad 0.82$ & 0.31 & 0.04 & 0.09 & 0.230 & $\begin{array}{lll}0.08 & 0.38 & 0.17\end{array}$ \\
\hline & & 0.15 & 0.12 & 0.03 & & & & & & & 0.01 & & & \\
\hline $0.83 \quad 0.89$ & $0.14 \quad 0.44$ & 0.19 & $\begin{array}{ll}0.11 & 0.03\end{array}$ & 0.12 & 0.13 & 0.03 & 0.03 & 0.02 & 0.11 & 0.11 & & & & \\
\hline & 0.24 & & & & & & & & & & & & & \\
\hline & 0.07 & & & & & & & & & & & & & \\
\hline & 0.05 & & & & & & & & & & & & & \\
\hline 0.11 & 0.77 & & & & & & & & & & & & & \\
\hline $\begin{array}{ll}0.44 & 0.07\end{array}$ & $\begin{array}{ll}0.21 & 0.51\end{array}$ & & & & & & & & & & & & 0.05 & 0.01 \\
\hline & 0.04 & & & & & & & & & & & & & \\
\hline
\end{tabular}

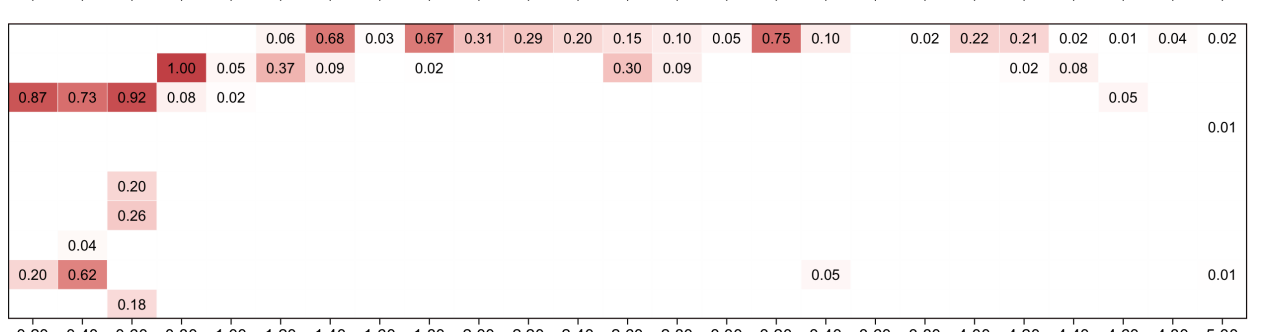

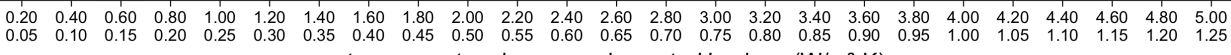
transparent and opaque elements $U$-values $\left(\mathrm{W} / \mathrm{m}^{2} \cdot \mathrm{K}\right)$

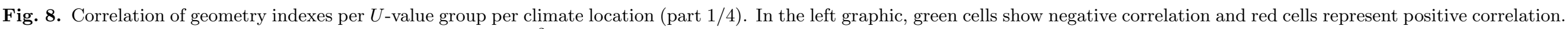

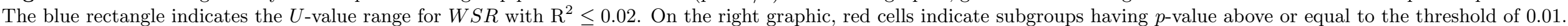




\section{Correlation}

Coefficient of determination

$\begin{array}{llllllllllllllllllllllllll}\text { WSR-W } & 0.04 & 0.08 & 0.09 & 0.06 & 0.03 & 0.02 & 0.00 & 0.00 & 0.01 & 0.00 & 0.00 & 0.00 & 0.00 & 0.00 & 0.00 & 0.00 & 0.01 & 0.00 & 0.02 & 0.01 & 0.02 & 0.00 & 0.02 & 0.03 & 0.03\end{array}$ WSR-S \begin{tabular}{llll|l|llllllllllllllllllllll} 
W.25 & 0.14 & 0.16 & 0.10 & 0.03 & 0.01 & 0.00 & 0.02 & 0.03 & 0.03 & 0.02 & 0.01 & 0.05 & 0.04 & 0.03 & 0.04 & 0.04 & 0.03 & 0.02 & 0.04 & 0.02 & 0.02 & 0.02 & 0.04 & 0.03
\end{tabular}

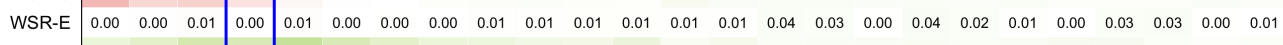

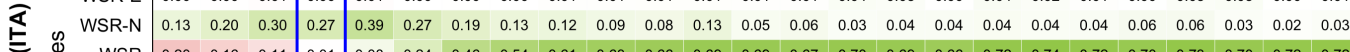

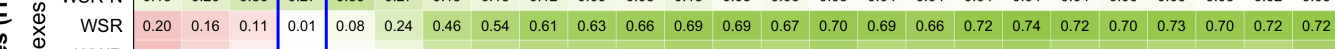

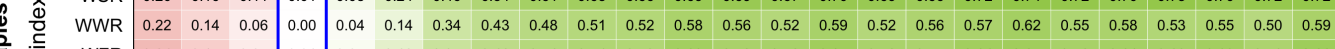
$\begin{array}{lllllllllllllllllllllllllll}\text { WFR } & 0.24 & 0.17 & 0.07 & 0.01 & 0.05 & 0.19 & 0.37 & 0.46 & 0.51 & 0.54 & 0.53 & 0.63 & 0.59 & 0.59 & 0.65 & 0.58 & 0.57 & 0.64 & 0.65 & 0.59 & 0.61 & 0.60 & 0.63 & 0.56 & 0.66\end{array}$

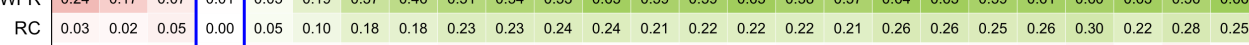

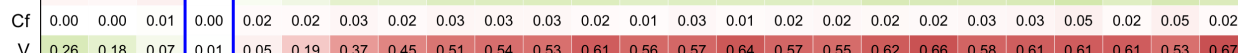

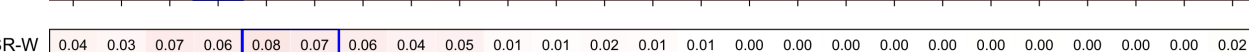
WSR-S $\begin{array}{llllllllllllllllllllllllllll} & 0.33 & 0.28 & 0.25 & 0.25 & 0.11 & 0.04 & 0.03 & 0.00 & 0.00 & 0.01 & 0.02 & 0.02 & 0.05 & 0.01 & 0.02 & 0.05 & 0.02 & 0.05 & 0.05 & 0.04 & 0.02 & 0.02 & 0.02 & 0.03 & 0.04\end{array}$

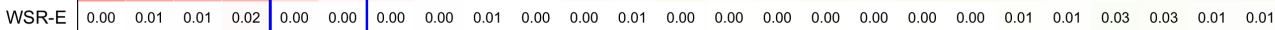

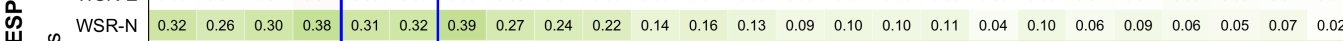

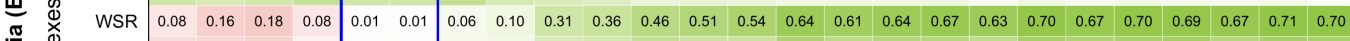

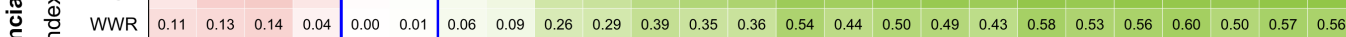

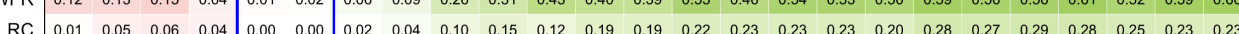

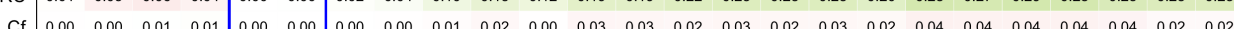

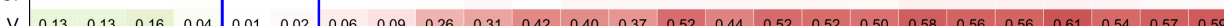

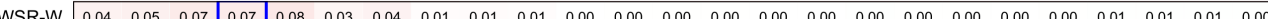

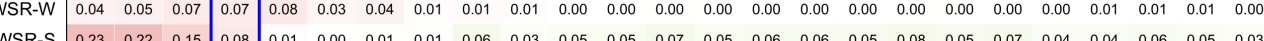

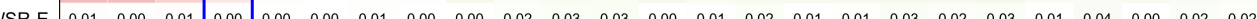

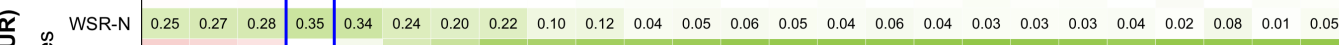

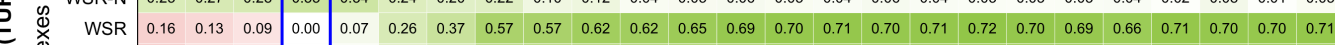

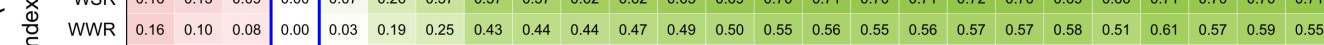

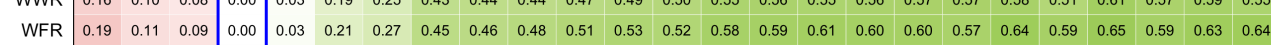

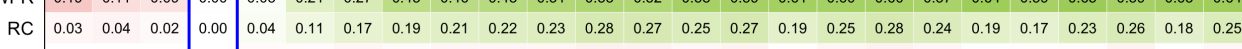

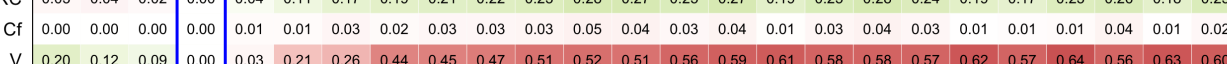
$\mathrm{V}$
$\mathrm{N}$

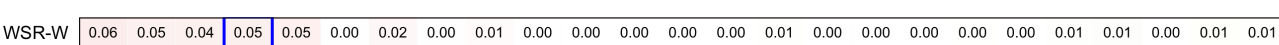
\begin{tabular}{l|lllllllllllllllllllllllll} 
WSR-S & 0.16 & 0.21 & 0.21 & 0.11 & 0.06 & 0.02 & 0.00 & 0.00 & 0.01 & 0.01 & 0.02 & 0.02 & 0.02 & 0.01 & 0.05 & 0.02 & 0.05 & 0.04 & 0.03 & 0.04 & 0.01 & 0.02 & 0.07 & 0.03 & 0.03
\end{tabular} $\begin{array}{llllllllllllllllllllllllll}\text { WSR-E } & 0.00 & 0.00 & 0.01 & 0.01 & 0.00 & 0.00 & 0.00 & 0.00 & 0.01 & 0.00 & 0.00 & 0.02 & 0.01 & 0.02 & 0.01 & 0.02 & 0.00 & 0.01 & 0.00 & 0.01 & 0.02 & 0.02 & 0.03 & 0.01 & 0.02\end{array}$

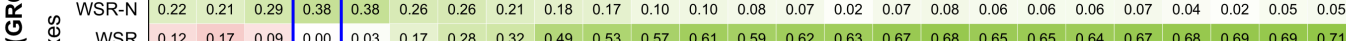
『 WSR $\begin{array}{llllllllllllllllllllllllll} & 0.12 & 0.17 & 0.09 & 0.00 & 0.03 & 0.17 & 0.28 & 0.32 & 0.49 & 0.53 & 0.57 & 0.61 & 0.59 & 0.62 & 0.63 & 0.67 & 0.68 & 0.65 & 0.65 & 0.64 & 0.67 & 0.68 & 0.69 & 0.69 & 0.71\end{array}$

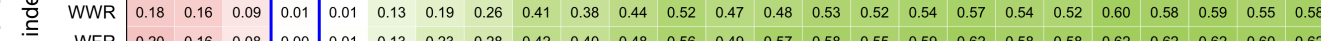
$\begin{array}{lllllllllllllllllllllllllllll} & \text { RFR } & 0.20 & 0.16 & 0.08 & 0.00 & 0.01 & 0.13 & 0.23 & 0.28 & 0.42 & 0.40 & 0.48 & 0.56 & 0.49 & 0.57 & 0.58 & 0.55 & 0.59 & 0.62 & 0.58 & 0.58 & 0.62 & 0.62 & 0.62 & 0.60 & 0.62\end{array}$ $\begin{array}{lllllllllllllllllllllllllll}\text { RC } & 0.01 & 0.05 & 0.03 & 0.00 & 0.02 & 0.07 & 0.09 & 0.11 & 0.17 & 0.20 & 0.17 & 0.24 & 0.22 & 0.20 & 0.20 & 0.22 & 0.21 & 0.22 & 0.20 & 0.18 & 0.21 & 0.22 & 0.24 & 0.25 & 0.25\end{array}$

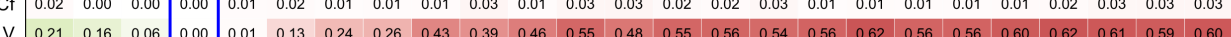

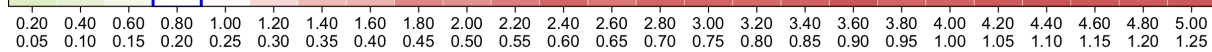
transparent and opaque elements $U$-values $\left(\mathrm{W} / \mathrm{m}^{2} \cdot \mathrm{K}\right)$
Calculated probability $p$-value

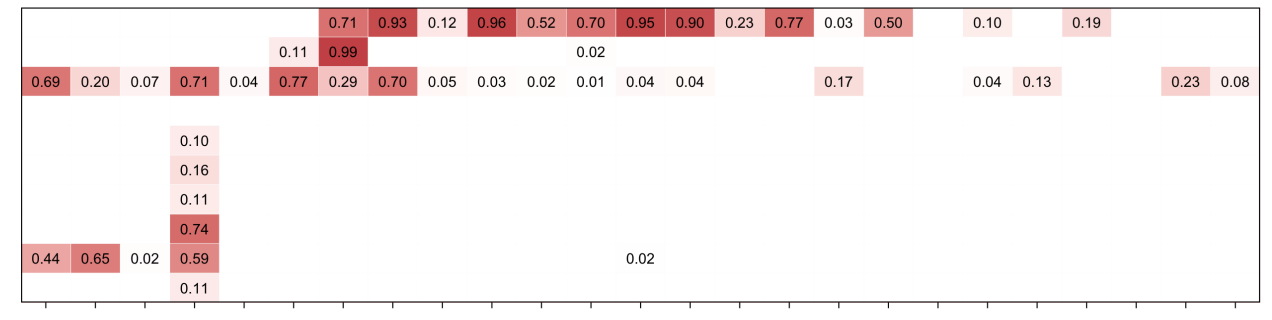

$0.41 \quad 0.62 \quad 0.00$

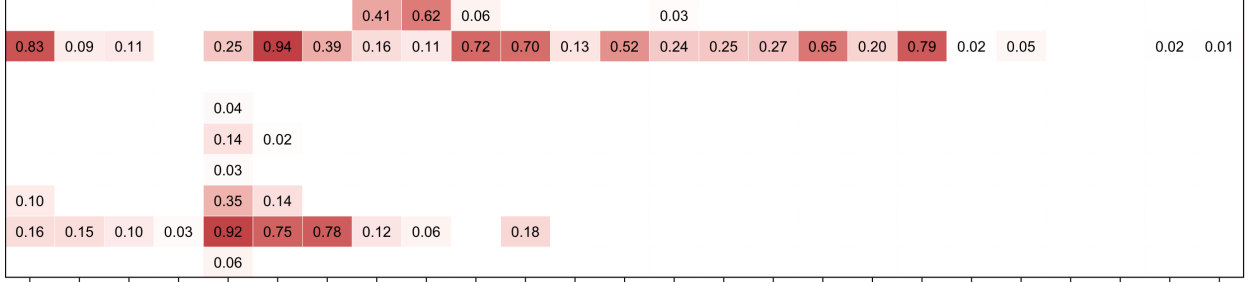

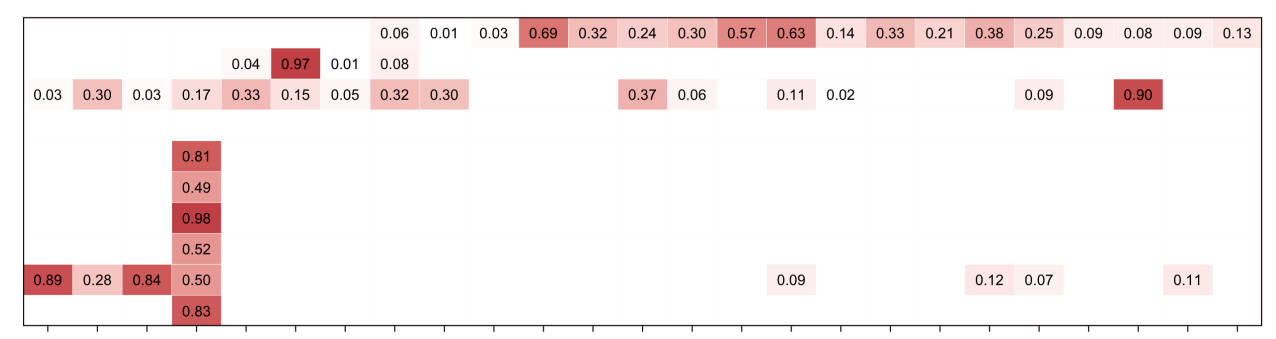

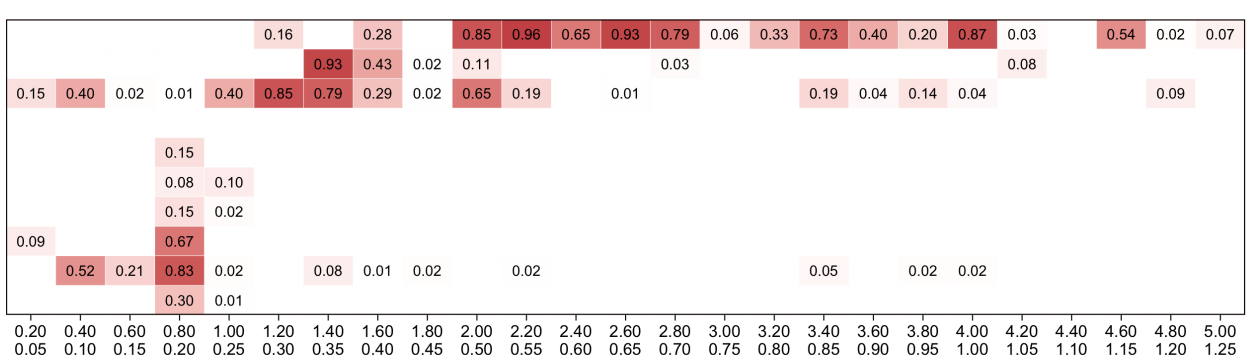

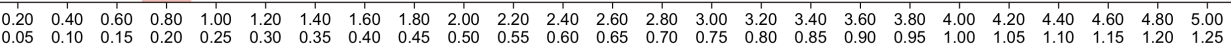

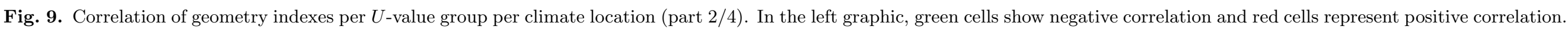

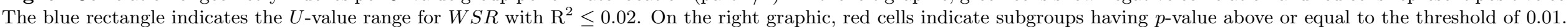




\section{Correlation}

Coefficient of determination

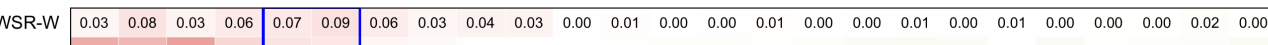
\begin{tabular}{l|lllllllllllllllllllllllllll|} 
WSR-S & 0.26 & 0.22 & 0.29 & 0.12 & 0.08 & 0.07 & 0.03 & 0.02 & 0.00 & 0.00 & 0.00 & 0.01 & 0.01 & 0.02 & 0.01 & 0.01 & 0.03 & 0.04 & 0.03 & 0.01 & 0.04 & 0.01 & 0.02 & 0.02 & 0.04
\end{tabular}

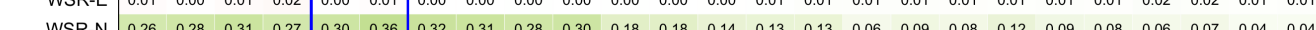

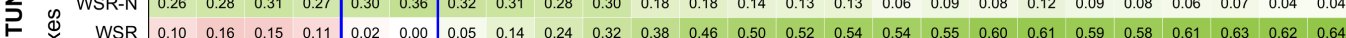
$\begin{array}{llllllllllllllllllllllllllll} & 0.01 & 0.65 & 0.02 & 0.04\end{array}$ $\begin{array}{lllllllllllllllll}. & \end{array}$

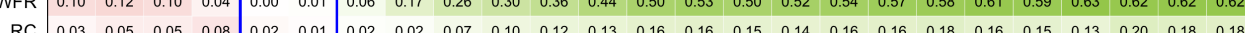

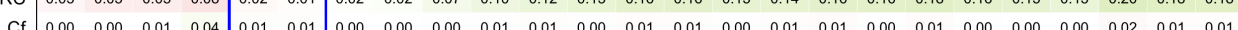

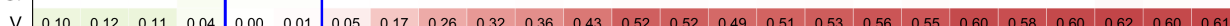
\begin{tabular}{lllll|l|llllllllllllllllllll} 
& \\
NR-W & 0.05 & 0.04 & 0.07 & 0.07 & 0.06 & 0.05 & 0.03 & 0.03 & 0.01 & 0.00 & 0.00 & 0.00 & 0.00 & 0.00 & 0.00 & 0.00 & 0.01 & 0.01 & 0.00 & 0.00 & 0.00 & 0.00 & 0.00 & 0.02 & 0.02
\end{tabular} $\begin{array}{lllllllllllllllllllllllllll} & \text { WSR-W } & 0.05 & 0.04 & 0.07 & 0.07 & 0.06 & 0.05 & 0.03 & 0.03 & 0.01 & 0.00 & 0.00 & 0.00 & 0.00 & 0.00 & 0.00 & 0.00 & 0.01 & 0.01 & 0.00 & 0.00 & 0.00 & 0.00 & 0.00 & 0.02 & 0.02\end{array}$

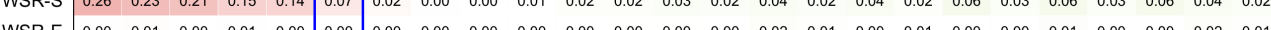

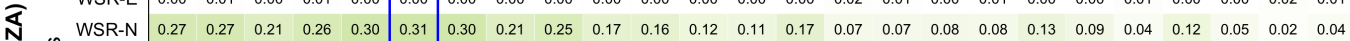
0
S WSR

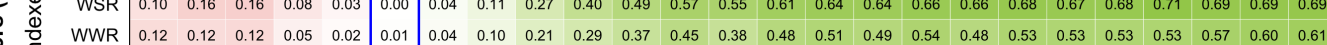

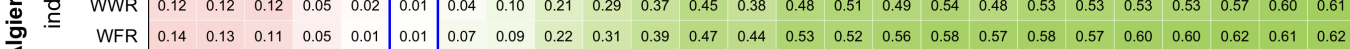

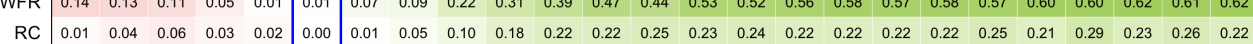
Cf \begin{tabular}{lllll|l|lllllllllllllllllllllll} 
& 0.00 & 0.00 & 0.01 & 0.01 & 0.01 & 0.00 & 0.00 & 0.01 & 0.01 & 0.04 & 0.04 & 0.03 & 0.05 & 0.03 & 0.04 & 0.02 & 0.02 & 0.02 & 0.01 & 0.03 & 0.02 & 0.05 & 0.01 & 0.03 & 0.02
\end{tabular} $\begin{array}{lllllllllllllllllllllllll}0.16 & 0.12 & 0.11 & 0.05 & 0.01 & 0.01 & 0.07 & 0.10 & 0.23 & 0.29 & 0.38 & 0.47 & 0.44 & 0.50 & 0.52 & 0.53 & 0.56 & 0.55 & 0.58 & 0.56 & 0.58 & 0.59 & 0.61 & 0.61 & 0.60\end{array}$

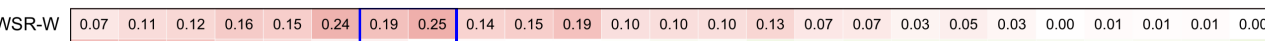
WSR-S \begin{tabular}{llllll|llllllllllllllllllll} 
& 0.21 & 0.20 & 0.19 & 0.12 & 0.10 & 0.05 & 0.05 & 0.00 & 0.01 & 0.00 & 0.00 & 0.01 & 0.05 & 0.02 & 0.08 & 0.05 & 0.07 & 0.06 & 0.06 & 0.06 & 0.05 & 0.03 & 0.05 & 0.05 & 0.10
\end{tabular}

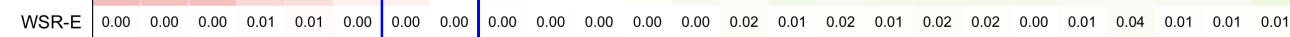

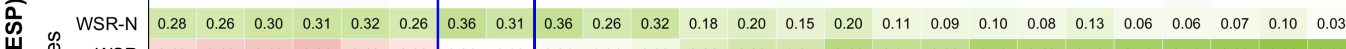

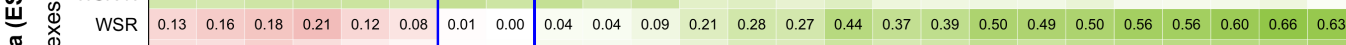

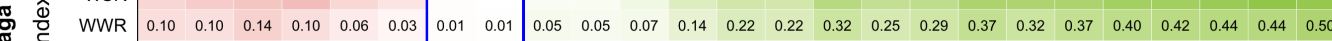
$\begin{array}{llllllllllllllllllllllllllll}\text { WFR } & 0.11 & 0.12 & 0.16 & 0.11 & 0.06 & 0.04 & 0.01 & 0.0 & 0.06 & 0.05 & 0.09 & 0.14 & 0.27 & 0.23 & 0.33 & 0.28 & 0.32 & 0.39 & 0.38 & 0.37 & 0.45 & 0.45 & 0.46 & 0.46 & 0.52\end{array}$ $\begin{array}{llllllllllllllllllllllllll}\mathrm{RC} & 0.03 & 0.05 & 0.05 & 0.11 & 0.05 & 0.05 & 0.00 & 0.00 & 0.01 & 0.01 & 0.03 & 0.07 & 0.08 & 0.10 & 0.18 & 0.14 & 0.14 & 0.19 & 0.22 & 0.16 & 0.19 & 0.21 & 0.23 & 0.27 & 0.23\end{array}$ Cf $\begin{array}{lllllllllllllllllllllllllll}0.00 & 0.01 & 0.00 & 0.03 & 0.01 & 0.01 & 0.00 & 0.00 & 0.00 & 0.00 & 0.00 & 0.01 & 0.00 & 0.01 & 0.03 & 0.02 & 0.02 & 0.03 & 0.05 & 0.02 & 0.02 & 0.03 & 0.04 & 0.06 & 0.02\end{array}$ $\checkmark$\begin{tabular}{llllll|lllllllllllllllllll}
0.12 & 0.12 & 0.15 & 0.10 & 0.06 & 0.04 & 0.01 & 0.00 & 0.05 & 0.06 & 0.09 & 0.15 & 0.26 & 0.21 & 0.32 & 0.30 & 0.31 & 0.39 & 0.36 & 0.37 & 0.47 & 0.43 & 0.43 & 0.45 & 0.54
\end{tabular}

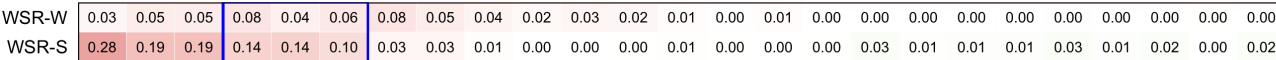
W WSR-E \begin{tabular}{cccc|ccccccccccccccccccccc}
0.00 & 0.00 & 0.00 & 0.00 & 0.01 & 0.00 & 0.00 & 0.00 & 0.00 & 0.00 & 0.01 & 0.00 & 0.00 & 0.01 & 0.01 & 0.01 & 0.00 & 0.01 & 0.01 & 0.01 & 0.01 & 0.01 & 0.01 & 0.02 & 0.00
\end{tabular}

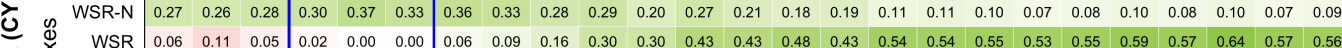

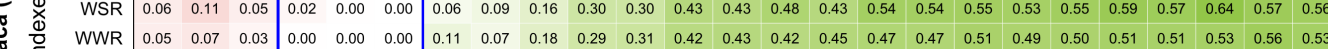
$\begin{array}{llllllllllllllllllllllllll}\text { WFR } & 0.05 & 0.08 & 0.02 & 0.00 & 0.01 & 0.00 & 0.11 & 0.11 & 0.21 & 0.31 & 0.38 & 0.45 & 0.50 & 0.48 & 0.51 & 0.54 & 0.52 & 0.57 & 0.57 & 0.55 & 0.58 & 0.57 & 0.57 & 0.62 & 0.59\end{array}$ $\begin{array}{lllllllllllllllllllllllllllll}\text { RC } & 0.02 & 0.04 & 0.02 & 0.03 & 0.02 & 0.00 & 0.00 & 0.02 & 0.03 & 0.06 & 0.06 & 0.14 & 0.08 & 0.15 & 0.07 & 0.15 & 0.17 & 0.15 & 0.10 & 0.16 & 0.17 & 0.17 & 0.19 & 0.15 & 0.09\end{array}$

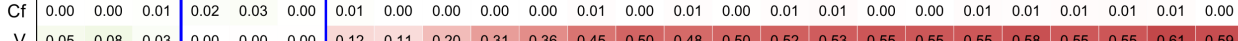
$\begin{array}{lllllllllllllllllllllllllllll}0.05 & 0.08 & 0.03 & 0.00 & 0.00 & 0.00 & 0.12 & 0.11 & 0.20 & 0.31 & 0.36 & 0.45 & 0.50 & 0.48 & 0.50 & 0.52 & 0.53 & 0.55 & 0.55 & 0.55 & 0.58 & 0.55 & 0.55 & 0.61 & 0.5\end{array}$

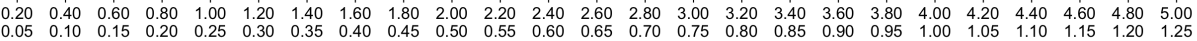
transparent and opaque elements $\mathrm{U}$-values $\left(\mathrm{W} / \mathrm{m}^{2} \cdot \mathrm{K}\right)$
Calculated probability

p-value

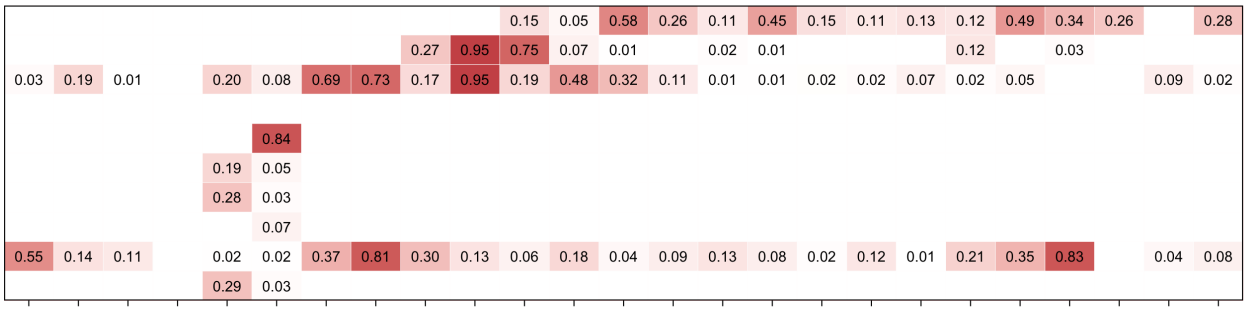

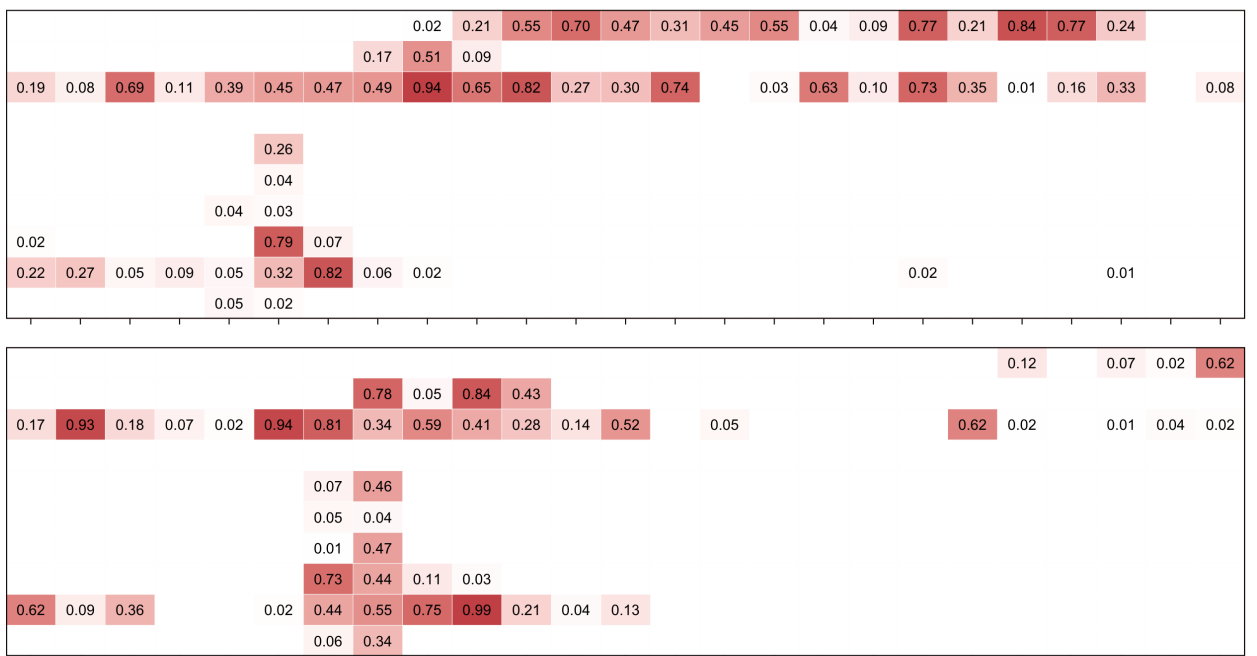

$\begin{array}{lllllllll}0.09 & 0.59 & 0.36 & 0.29 & 0.06 & 0.25 & 0.52 & 0.23\end{array}$ $\begin{array}{llll}0.07 & 0.01 & 0.02\end{array}$

$\begin{array}{lllllllll}0.79 & 0.12 & 0.57 & 0.35 & 0.03 & 0.65 & 0.26 & 0.14\end{array}$

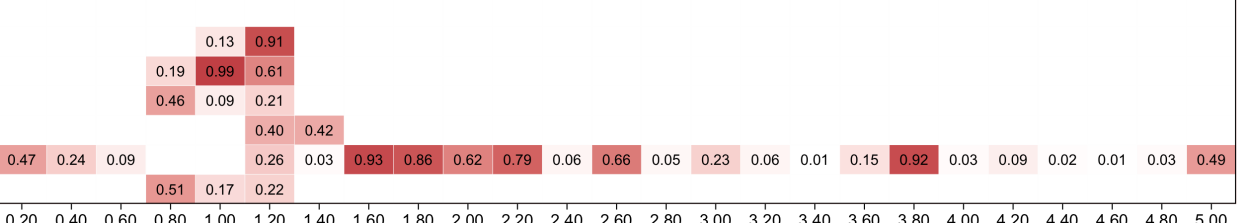

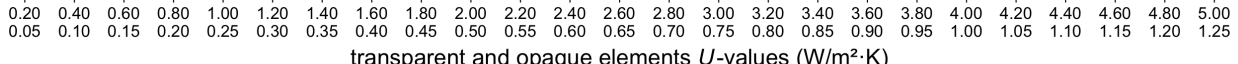

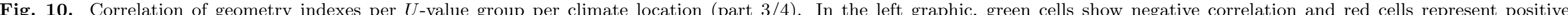

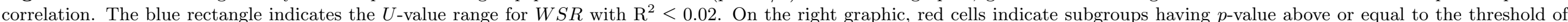
0.01 . 


\section{Correlation}

Coefficient of determination

WSR-W \begin{tabular}{llllllll|ll|lllllllllllllll|}
0.04 & 0.04 & 0.09 & 0.05 & 0.10 & 0.16 & 0.12 & 0.10 & 0.15 & 0.15 & 0.09 & 0.09 & 0.07 & 0.07 & 0.03 & 0.03 & 0.02 & 0.01 & 0.02 & 0.00 & 0.00 & 0.00 & 0.00 & 0.00 & 0.00
\end{tabular}

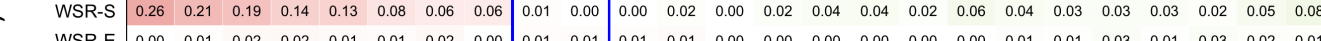

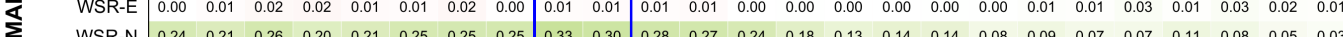
J 0 \&

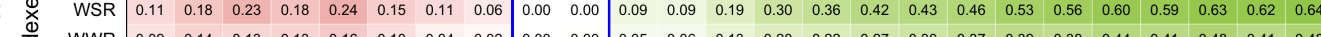

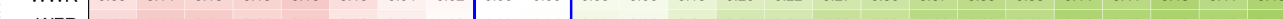
$\begin{array}{lllllllllllllllllllllllllll} & \text { RC } & 0.11 & 0.10 & 0.15 & 0.13 & 0.15 & 0.08 & 0.05 & 0.02 & 0.00 & 0.01 & 0.08 & 0.06 & 0.15 & 0.25 & 0.25 & 0.33 & 0.33 & 0.41 & 0.43 & 0.40 & 0.48 & 0.46 & 0.50 & 0.48 & 0.52\end{array}$ $\begin{array}{lllllllllllllllllllllllllll}\text { RC } & 0.02 & 0.05 & 0.09 & 0.08 & 0.12 & 0.08 & 0.07 & 0.05 & 0.01 & 0.00 & 0.03 & 0.05 & 0.08 & 0.12 & 0.15 & 0.17 & 0.15 & 0.15 & 0.23 & 0.22 & 0.24 & 0.20 & 0.21 & 0.24 & 0.21\end{array}$ V $\begin{array}{lllllllllllllllllllllllllll}0.11 & 0.17 & 0.15 & 0.13 & 0.14 & 0.08 & 0.05 & 0.1 & 0.00 & 0.1 & 0.08 & 0.06 & 0.16 & 0.26 & 0.24 & 0.32 & 0.33 & 0.42 & 0.43 & 0.41 & 0.47 & 0.46 & 0.49 & 0.46 & 0.52\end{array}$

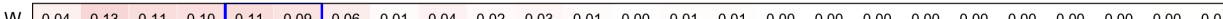

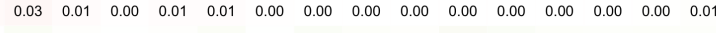
$\begin{array}{lllllllllllllllllllllllllll}\text { WSR-S } & 0.17 & 0.15 & 0.11 & 0.16 & 0.06 & 0.04 & 0.03 & 0.02 & 0.00 & 0.0 & 0.03 & 0.01 & 0.00 & 0.01 & 0.03 & 0.01 & 0.03 & 0.02 & 0.01 & 0.04 & 0.03 & 0.02 & 0.02 & 0.02 & 0.02\end{array}$

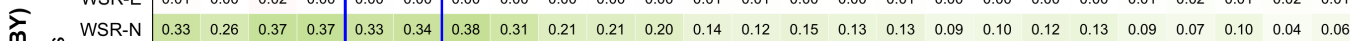

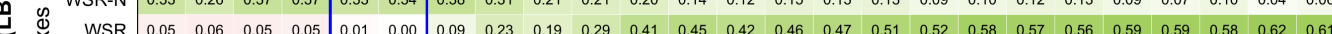
\begin{tabular}{llllllllllllllllllllllll}
\hline & 0.02
\end{tabular} . $\begin{array}{lllllllllllllllllllllllllllll}\text { WFR } & 0.06 & 0.02 & 0.01 & 0.00 & 0.00 & 0.02 & 0.14 & 0.27 & 0.26 & 0.34 & 0.42 & 0.47 & 0.47 & 0.56 & 0.48 & 0.56 & 0.55 & 0.57 & 0.59 & 0.59 & 0.64 & 0.61 & 0.65 & 0.64 & 0.67\end{array}$ \begin{tabular}{r|llll|lllllllllllllllllllll} 
RC & 0.01 & 0.04 & 0.04 & 0.07 & 0.02 & 0.00 & 0.01 & 0.05 & 0.03 & 0.05 & 0.12 & 0.10 & 0.11 & 0.09 & 0.12 & 0.13 & 0.12 & 0.14 & 0.11 & 0.16 & 0.14 & 0.16 & 0.13 & 0.17 & 0.16 \\
Cf & 0.00 & 0.01 & 0.02 & 0.05 & 0.02 & 0.01 & 0.00 & 0.00 & 0.00 & 0.00 & 0.00 & 0.00 & 0.00 & 0.00 & 0.01 & 0.00 & 0.00 & 0.00 & 0.00 & 0.01 & 0.00 & 0.00 & 0.00 & 0.00 & 0.00
\end{tabular}

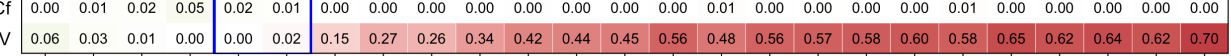
\begin{tabular}{llllllll|llllllllllllllllll} 
WSR-W & 0.18 & 0.14 & 0.18 & 0.24 & 0.24 & 0.27 & 0.22 & 0.21 & 0.18 & 0.15 & 0.14 & 0.10 & 0.14 & 0.10 & 0.09 & 0.04 & 0.03 & 0.03 & 0.02 & 0.04 & 0.04 & 0.01 & 0.03 & 0.01 & 0.01
\end{tabular} $\begin{array}{lllllllllllllllllllllllllll}\text { WSR-S } & 0.21 & 0.21 & 0.20 & 0.09 & 0.07 & 0.06 & 0.03 & 0.03 & 0.00 & 0.01 & 0.00 & 0.00 & 0.01 & 0.01 & 0.04 & 0.03 & 0.02 & 0.02 & 0.02 & 0.04 & 0.02 & 0.00 & 0.03 & 0.01 & 0.02\end{array}$

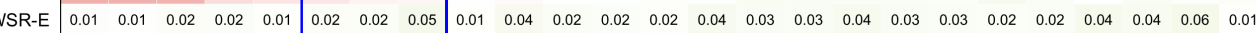

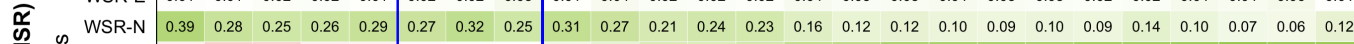

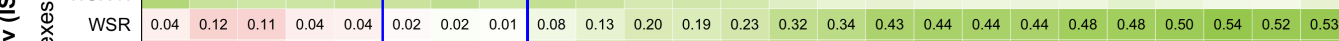

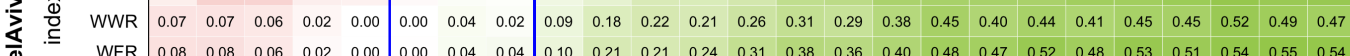
WFR $\begin{array}{lllllllllllllllllllllllllllll}\text { W.08 } & 0.08 & 0.06 & 0.02 & 0.00 & 0.00 & 0.04 & 0.04 & 0.10 & 0.21 & 0.21 & 0.24 & 0.31 & 0.38 & 0.36 & 0.40 & 0.48 & 0.47 & 0.52 & 0.48 & 0.53 & 0.51 & 0.54 & 0.55 & 0.54\end{array}$ $\begin{array}{lllllllllllllllllllllllllll}\text { RC } & 0.00 & 0.05 & 0.06 & 0.03 & 0.04 & 0.02 & 0.00 & 0.00 & 0.02 & 0.01 & 0.04 & 0.04 & 0.05 & 0.08 & 0.09 & 0.13 & 0.16 & 0.08 & 0.09 & 0.15 & 0.11 & 0.11 & 0.13 & 0.09 & 0.14\end{array}$ Cf $\begin{array}{llllllllllllllllllllllllll}0.01 & 0.01 & 0.02 & 0.01 & 0.03 & 0.02 & 0.00 & 0.01 & 0.00 & 0.01 & 0.00 & 0.00 & 0.00 & 0.00 & 0.00 & 0.01 & 0.01 & 0.00 & 0.00 & 0.01 & 0.00 & 0.00 & 0.00 & 0.00 & 0.00\end{array}$ $\checkmark \begin{array}{llllllllllllllllllllllllll}0.08 & 0.08 & 0.06 & 0.01 & 0.00 & 0.00 & 0.03 & 0.04 & 0.10 & 0.20 & 0.23 & 0.23 & 0.30 & 0.38 & 0.35 & 0.39 & 0.47 & 0.46 & 0.53 & 0.49 & 0.52 & 0.49 & 0.53 & 0.55 & 0.55\end{array}$

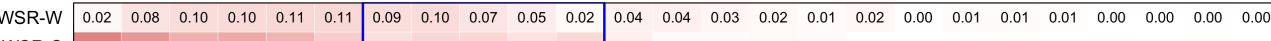
WSR-S $\begin{array}{llllllllllllllllllllllllllll} & 0.37 & 0.30 & 0.23 & 0.25 & 0.21 & 0.14 & 0.09 & 0.11 & 0.11 & 0.08 & 0.10 & 0.05 & 0.02 & 0.01 & 0.02 & 0.01 & 0.00 & 0.00 & 0.01 & 0.01 & 0.00 & 0.00 & 0.00 & 0.01 & 0.00\end{array}$

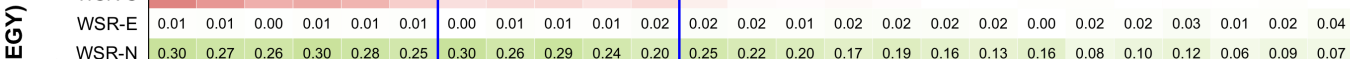

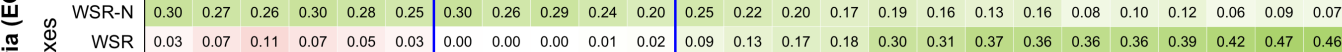

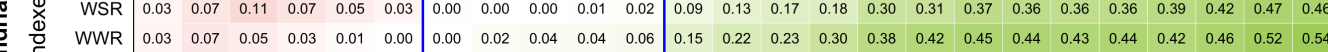

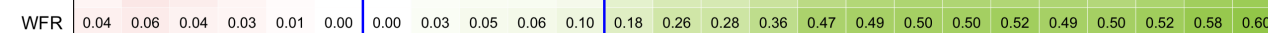

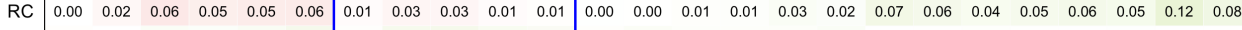
Cf $\begin{array}{llllllllllllllllllllllllllll}0.01 & 0.00 & 0.03 & 0.02 & 0.03 & 0.05 & 0.01 & 0.05 & 0.06 & 0.04 & 0.03 & 0.01 & 0.02 & 0.02 & 0.01 & 0.02 & 0.02 & 0.00 & 0.00 & 0.01 & 0.00 & 0.00 & 0.00 & 0.00 & 0.00\end{array}$ $\begin{array}{llllllllllllllllllllllllll}0.05 & 0.06 & 0.04 & 0.02 & 0.01 & 0.00 & 0.00 & 0.03 & 0.05 & 0.07 & 0.10 & 0.18 & 0.28 & 0.29 & 0.35 & 0.46 & 0.49 & 0.51 & 0.49 & 0.51 & 0.48 & 0.49 & 0.53 & 0.58 & 0.60\end{array}$

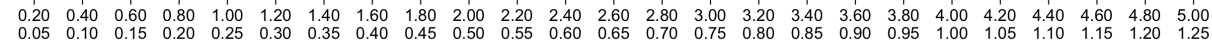
transparent and opaque elements $U$-values $\left(\mathrm{W} / \mathrm{m}^{2} \cdot \mathrm{K}\right)$
Calculated probability

$p$-value

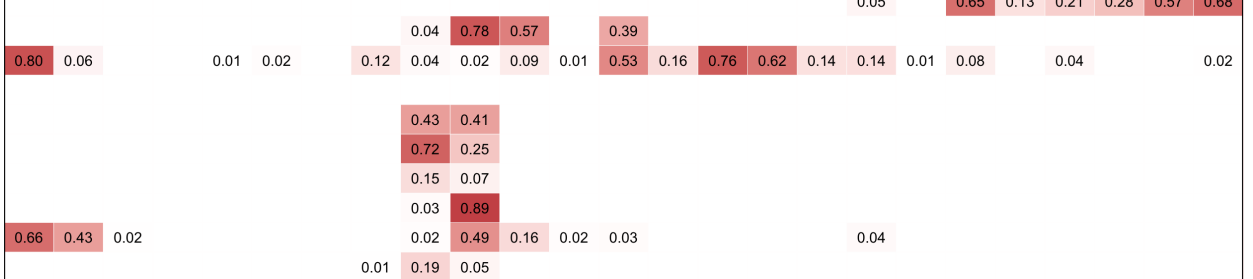

\begin{tabular}{|llllllllllllllll|}
\hline & 0.01 & 0.01 & 0.27 & 0.05 & 0.03 & 0.29 & 0.74 & 0.46 & 0.84 & 0.43 & 0.76 & 0.84 & 0.83 & 0.25 & 0.04 \\
\hline
\end{tabular}
$\begin{array}{llllllll}0.020 & 0.01 & 0.27 & 0.05 & 0.03 & 0.29 & 0.70 & 0\end{array}$

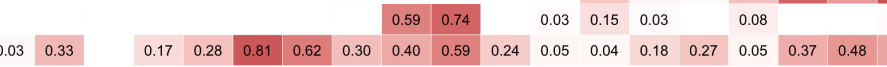

$0.42 \quad 0.68 \quad 0.04$

$0.06 \quad 0.06$ 0.010 .22

$\begin{array}{ll}0.16 & 0.71 \\ 0.26 & 0.79\end{array}$

$0.37 \quad 0.02$

$\begin{array}{lllllllllllllllllllllll}0.35 & 0.82 & 0.04 & 0.26 & 0.94 & 0.39 & 0.59 & 0.26 & 0.57 & 0.39 & 0.85 & 0.07 & 0.62 & 0.33 & 0.54 & 0.67 & 0.08 & 0.86 & 0.15 & 0.70 & 0.23 & 0.50\end{array}$

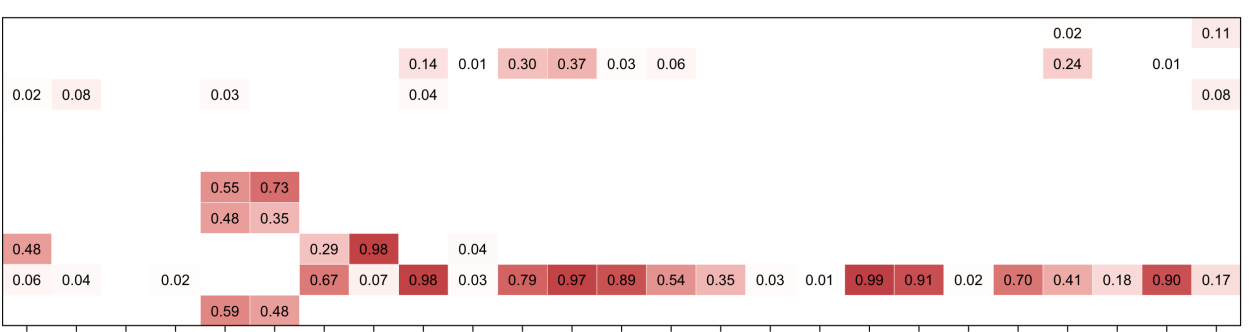

\begin{tabular}{|llllllllllllll}
\hline & 0.02 & 0.27 & 0.01 & 0.04 & 0.10 & 0.56 & 0.89 & 0.33 & 0.75
\end{tabular}

$\begin{array}{lllllll}0.08 & 0.03 & 0.14 & 0.03 & 0.06 & 0.02\end{array}$

0.02

0.56

\section{$\begin{array}{llll}0.15 & 0.64 & 0.77 & 0.09\end{array}$}

$\begin{array}{lll}0.03 & 0.65 & 0.42 \\ 0.04 & 0.71 & 0.69\end{array}$

0.03

$\begin{array}{llllll}0.02 & 0.12 & 0.19 & 0.21 & 0.04 & 0.02\end{array}$

0.03

$\begin{array}{llllllll}0.63 & 0.33 & 0.11 & 0.29 & 0.40 & 0.14 & 0.39 & 0.52\end{array}$

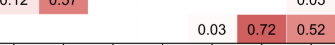

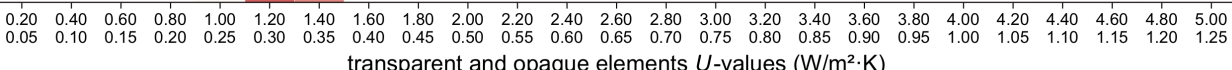

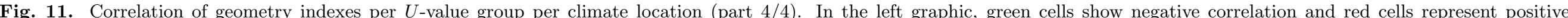

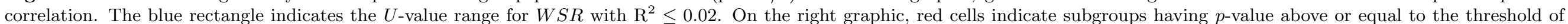
0.01 . 
Relatively to window indexes ( $W F R, W W R$, and $W S R$ ), all locations present moderate to strong negative correlation for higher $U$-values, that tend to decrease for smaller $U$-values. Hence, for high $U$-values, the glazing areas improve the buildings performance by reducing the energy consumption. For very low $U$-values, the windows begin to have weak positive correlation, thus increasing the energy consumption of the buildings. However, this effect is mitigated for southern latitudes.

The influence of windows orientation is also important. For low $U$-values, the $W S R$ - $N$ present very weak and weak negative correlation, in all locations, thus reducing the energy consumption. For southern locations, this effect is extendable to high $U$-values. For very low $U$-values, $W S R$ - $S$ has weak positive correlation, for all locations. However, for southern locations, very weak positive correlation tends to occur also for low $U$-values. Regarding the $W S R-W$ index, it presents very weak positive correlation for very low $U$-values, in northern locations; extending for low $U$-values for southern locations. However, for Malaga (ESP), Casablanca (MAR) and Tel Aviv (ISR), WSR-W presents weak positive correlation even for middle range $U$-values.

Also noticeable is the fact that the $U$-values range of none or very weak correlation in Figs. 8 to 11. especially for the window-based indexes (marked as blue rectangles), nearly overlaps the position of lower energy consumption for all locations in Figs. 6 and 7 (marked as blue vertical line). Table 9 summarizes the most adequate $U$-values for energy consumption (lowest buildings energy consumption average; marked in Figs. 6 and 7 as vertical blue lines) and building geometry (WSR with $\mathrm{R}^{2} \leq 0.02$; marked in Fig 8 to 11 as blue rectangles).

Table 9. Most adequate $U$-values (transparent and opaque elements) per location.

\begin{tabular}{|c|c|c|c|c|c|}
\hline \multirow[b]{2}{*}{ City } & \multirow[b]{2}{*}{ Country } & \multicolumn{2}{|c|}{$\begin{array}{c}\text { Energy most adequate } U \text {-values } \\
\left(\mathrm{W} \cdot \mathrm{m}^{-2} \cdot \mathrm{K}^{-1}\right)\end{array}$} & \multicolumn{2}{|c|}{$\begin{array}{l}\text { Geometry most adequate } U \text {-values } \\
\qquad\left(\mathrm{W} \cdot \mathrm{m}^{-2} \cdot \mathrm{K}^{-1}\right)\end{array}$} \\
\hline & & Transparent & Opaque & Transparent & Opaque \\
\hline Marseille & France (FRA) & 0.80 & 0.20 & 0.80 & 0.20 \\
\hline Podgorica & Montenegro (MNE) & 0.80 & 0.20 & 0.60 & 0.15 \\
\hline Istanbul & Turkey (TUR) & 0.60 & 0.15 & 0.60 & 0.15 \\
\hline Izmir & Turkey (TUR) & 1.00 & 0.25 & 0.80 & 0.20 \\
\hline Athens & Greece (GRC) & 1.00 & 0.25 & 0.80 & 0.20 \\
\hline Tunis & Tunisia (TUN) & 1.40 & 0.35 & $1.00-1.20$ & $0.25-0.30$ \\
\hline Algiers & Algeria (DZA) & 1.60 & 0.40 & 1.20 & 0.30 \\
\hline Malaga & Spain (ESP) & 2.20 & 0.55 & $1.40-1.60$ & $0.35-0.40$ \\
\hline Alexandria & Egypt (EGY) & 2.60 & 0.65 & $1.40-2.20$ & $0.35-0.55$ \\
\hline
\end{tabular}




\section{Discussion}

The results of this study show some relation between the construction elements thermal transmittance and the buildings energy consumption and geometry. Higher $U$-values lead to a decrease of the cooling energy consumption and to an increase of heating energy consumption, thus being more favorable for cooling. And the opposite is true for lower $U$-values (more favorable for heating). However, the variations of the cooling and heating energy consumption depend on the specific climate. In northern Mediterranean locations, smaller $U$-values lead to lower energy consumptions, except for very low $U$-values which contribute to a slight overheating. On the other hand, there is little advantage on using higher $U$-values, since the cooling demands only decrease slightly and the heating demands tend to greatly increase. For lower latitudes, the cooling demands (and the overall energy consumption) increase greatly for smaller $U$-values, as they hinder the heat release from the building. Contrariwise, the amplitude of energy consumption remains practically constant for high and mid-range $U$-values. Therefore, the most suitable $U$-values tend to be higher for lower latitudes, where the heat release and preventing excessive heat accumulation become important (see Figs. 6 and 7). Moreover, lower $U$-values always reduce the building heating demands, for all locations; especially in northern latitudes, where the heating needs are bigger.

Concerning building size and geometry, larger buildings have worse energy performance for high and intermediate $U$-values. This effect is mitigated for low $U$-values, especially in northern latitudes, where it is even reversed for very low $U$-values. For this range, the heating energy is always null for all locations (Figs. 6 and 7), so it can be concluded that bigger buildings with very high insulation tend to require less cooling energy; especially in northern locations, where this phenomenon is more noticeable. As for the building relative compactness, its tendency is to be the opposite of the building size effect, however with a much weaker correlation with the energy performance.

For very low $U$-values, larger windows are a worsening factor towards the energy performance, especially for northern latitudes. For higher $U$-values this effect is reverted, as the windows size become an improving factor towards the energy performance. This reversion is quicker (i.e., takes place at lower $U$-values) for higher latitudes. Therefore, higher $U$-values allow for larger windows to increase the heat release, and the lower the latitude, the wider the interval of small $U$-values that should be avoided. The influence of shadowing elements should have impact in these windowrelated results and should be studied in future works.

Regarding the main windows orientations exposed to solar radiation (South and West; the East orientation does not present significant impact in the building performance), the lower the latitude the wider the interval of small $U$-values that worsens the energy performance. Thus, while in 
northern countries South- and West-faced windows only worsen the energy performance for low $U$-values, in southern countries this happens for a wide range of $U$-values. On the other hand, for windows facing North, the lower the latitude, the wider the $U$-value range that improves the energy performance. Hence, while in northern countries North-faced windows only improve the energy performance for low $U$-values, in southern countries this happens for a wide range of $U$-values. Moreover, North-faced windows start having a positive influence towards the energy performance even before the most favorable $U$-value interval. In summary, low $U$-values for windows faced South and West worsen the energy performance, while for windows faced North they increase the energy performance; being that the range of low $U$-values where this occurs becomes wider for lower latitudes, due to warmer climates.

As discussed before for the energy consumption, the most suitable $U$-values for the geometry indexes also tend to increase for lower latitudes, where the heat release becomes more important due to warmer climates. Moreover, the adequate $U$-value interval that combines the best performance and the geometry freedom becomes wider for lower latitudes, thus allowing greater freedom to select a $U$-value in the interval. These geometry indexes can thus serve as support and guide to building designers, when opting for certain $U$-values.

\section{Conclusion}

In this study, several buildings' geometries were randomly generated, with random $U$-values for roofs, exterior walls, suspended floors, exterior doors, and windows. The energy performance of those buildings was evaluated and the range of annual energy consumption and the correlation with six geometry-based indexes were determined for each pair of opaque and transparent elements $U$-values, for sixteen locations in the Mediterranean region. The main conclusions are the following:

- in northern latitudes, as the $U$-values get lower, the buildings energy consumption and the group energy performance amplitude decrease;

- in southern countries, for very low $U$-values, the tendency inverts and the average energy consumption and the performance amplitude increase, but remain practically constant for the higher $U$-values;

- bigger buildings worsen the energy performance for high and intermediate $U$-values;

- in northern locations, for very low $U$-values, the bigger the building the less energy it consumes;

- in northern latitudes, for very low $U$-values, the window indexes begin to have weak positive correlation, particularly for WSR orientations West and South, thus tending to increase the energy consumption of the buildings; 
- in southern latitudes, for low $U$-values, the windows dimensions only slightly affect the building performance;

- for low $U$-values, North-faced windows have a positive influence towards the energy performance, even before the most suitable $U$-value interval;

- the most adequate $U$-value interval, which allows geometric freedom and to reduce the heating demands without raising too much the cooling needs, tends to be higher in the $U$-value scale for lower latitudes;

- the most favorable $U$-value interval also tends to be wider for southern latitudes, thus allowing greater freedom to select a $U$-value in the interval;

- when the energy consumption is at the lowest in the $U$-values scale, geometry-based indexes present none or very weak correlations, thus meaning that not only the building performance improves but allows building designers to be freer to explore alternative forms and window designs.

\section{Acknowledgements}

The research presented has been developed under the Energy for Sustainability Initiative of the University of Coimbra (UC). This work has been financed by the Portuguese Foundation for Science and Technology (FCT) and by the European Regional Development Fund (FEDER) through COMPETE 2020 - Operational Program for Competitiveness and Internationalization (POCI) in the framework of the research project Ren4EEnIEQ (PTDC/EMS-ENE/3238/2014, POCI-010145-FEDER-016760, and LISBOA-01-0145-FEDER-016760). Eugénio Rodrigues acknowledges the support provided by the FCT, under Postdoc grant SFRH/BPD/99668/2014.

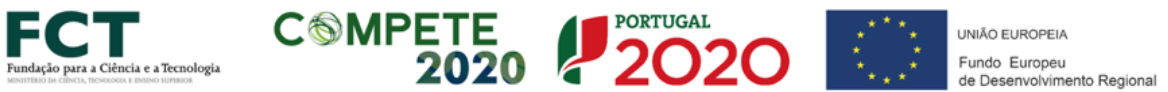

\section{References}

[1] World Energy Outlook 2014, Tech. Rep., International Energy Agency, URL https://www.iea.org/ publications/freepublications/publication/WE02014.pdf, 2014.

[2] J. Lee, J. Kim, D. Song, J. Kim, C. Jang, Impact of external insulation and internal thermal density upon energy consumption of buildings in a temperate climate with four distinct seasons, Renewable and Sustainable Energy Reviews 75 (2017) 1081-1088, ISSN 13640321, doi:10.1016/j.rser.2016.11.087

[3] K. Loukaidou, A. Michopoulos, T. Zachariadis, Nearly-zero Energy Buildings: Cost-optimal Analysis of Building Envelope Characteristics, Procedia Environmental Sciences 38 (2017) 20-27, ISSN 18780296, doi:10.1016/j. proenv.2017.03.069 
[4] F. Goia, B. Time, A. Gustavsen, Impact of Opaque Building Envelope Configuration on the Heating and Cooling Energy Need of a Single Family House in Cold Climates, Energy Procedia 78 (1876) (2015) 2626-2631, ISSN 18766102, doi:10.1016/j.egypro.2015.11.328

[5] T. van Hooff, B. Blocken, J. Hensen, H. Timmermans, On the predicted effectiveness of climate adaptation measures for residential buildings, Building and Environment 83 (2015) 142-158, ISSN 03601323, doi:10.1016/ j.buildenv.2014.10.006.

[6] L. Pajek, B. Hudobivnik, R. Kunič, M. Košir, Improving thermal response of lightweight timber building envelopes during cooling season in three European locations, Journal of Cleaner Production 156 (2017) 939952, ISSN 09596526, doi:10.1016/j.jclepro.2017.04.098

[7] K. Tsikaloudaki, K. Laskos, T. Theodosiou, D. Bikas, The energy performance of windows in Mediterranean regions, Energy and Buildings 92 (2015) 180-187, ISSN 03787788, doi:10.1016/j.enbuild.2015.01.059

[8] C. Marino, A. Nucara, M. Pietrafesa, Does window-to-wall ratio have a significant effect on the energy consumption of buildings? A parametric analysis in Italian climate conditions, Journal of Building Engineering 13 (June) (2017) 169-183, ISSN 23527102, doi:10.1016/j.jobe.2017.08.001

[9] A. R. Amaral, E. Rodrigues, A. R. Gaspar, Á. Gomes, A thermal performance parametric study of window type, orientation, size and shadowing effect, Sustainable Cities and Society 26 (2016) 456-465, doi:10.1016/j. Scs.2016.05.014,

[10] P. Ma, L.-S. Wang, N. Guo, Maximum window-to-wall ratio of a thermally autonomous building as a function of envelope U-value and ambient temperature amplitude, Applied Energy 146 (2015) 84-91, ISSN 03062619, doi:10.1016/j.apenergy.2015.01.103.

[11] X. Su, X. Zhang, Environmental performance optimization of window-wall ratio for different window type in hot summer and cold winter zone in China based on life cycle assessment, Energy and Buildings 42 (2) (2010) 198-202, ISSN 03787788, doi:10.1016/j.enbuild.2009.08.015.

[12] F. Goia, Search for the optimal window-to-wall ratio in office buildings in different European climates and the implications on total energy saving potential, Solar Energy 132 (2016) 467-492, ISSN 0038092X, doi:10.1016/j. solener.2016.03.031.

[13] L.-S. Wang, P. Ma, E. Hu, D. Giza-Sisson, G. Mueller, N. Guo, A study of building envelope and thermal mass requirements for achieving thermal autonomy in an office building, Energy and Buildings 78 (2014) 79-88, ISSN 03787788, doi:10.1016/j.enbuild.2014.04.015.

[14] E. Rodrigues, A. R. Amaral, A. R. Gaspar, Á. Gomes, How reliable are geometry-based building indices as thermal performance indicators?, Energy Conversion and Management 101 (2015) 561-578, ISSN 01968904, doi:10.1016/j.enconman.2015.06.011

[15] E. Rodrigues, N. Soares, M. S. Fernandes, A. R. Gaspar, Á. Gomes, J. J. Costa, An integrated energy performance-driven generative design methodology to foster modular lightweight steel framed dwellings in hot climates, Energy for Sustainable Development 44 (2018) 21-36, ISSN 09730826, doi:10.1016/j.esd.2018.02.006.

[16] C. Baglivo, P. M. Congedo, A. Fazio, D. Laforgia, Multi-objective optimization analysis for high efficiency external walls of zero energy buildings (ZEB) in the Mediterranean climate, Energy and Buildings 84 (2014) 483-492, ISSN 03787788, doi:10.1016/j.enbuild.2014.08.043

[17] T. M. Echenagucia, A. Capozzoli, Y. Cascone, M. Sassone, The early design stage of a building envelope: Multiobjective search through heating, cooling and lighting energy performance analysis, Applied Energy 154 (2015) 577-591, ISSN 03062619, doi:10.1016/j.apenergy.2015.04.090.

[18] F. Ascione, R. F. De Masi, F. de Rossi, S. Ruggiero, G. P. Vanoli, Optimization of building envelope design for nZEBs in Mediterranean climate: Performance analysis of residential case study, Applied Energy 183 (2016) 
938-957, ISSN 03062619, doi:10.1016/j.apenergy.2016.09.027.

[19] F. Goia, M. Haase, M. Perino, Optimizing the configuration of a façade module for office buildings by means of integrated thermal and lighting simulations in a total energy perspective, Applied Energy 108 (2013) 515-527, ISSN 03062619, doi:10.1016/j.apenergy.2013.02.063

[20] Y. Cascone, A. Capozzoli, M. Perino, Optimisation analysis of PCM-enhanced opaque building envelope components for the energy retrofitting of office buildings in Mediterranean climates, Applied Energy 211 (November 2017) (2018) 929-953, ISSN 03062619, doi:10.1016/j.apenergy.2017.11.081.

[21] S. Attia, M. Hamdy, W. O'Brien, S. Carlucci, Assessing gaps and needs for integrating building performance optimization tools in net zero energy buildings design, Energy and Buildings 60 (2013) 110-124, ISSN 03787788, doi:10.1016/j.enbuild.2013.01.016.

[22] V. Machairas, A. Tsangrassoulis, K. Axarli, Algorithms for optimization of building design: A review, Renewable and Sustainable Energy Reviews 31 (1364) (2014) 101-112, ISSN 13640321, doi:10.1016/j.rser.2013.11.036

[23] A.-T. Nguyen, S. Reiter, P. Rigo, A review on simulation-based optimization methods applied to building performance analysis, Applied Energy 113 (2014) 1043-1058, ISSN 03062619, doi:10.1016/j.apenergy.2013.08. 061 .

[24] L. De Boeck, S. Verbeke, A. Audenaert, L. De Mesmaeker, Improving the energy performance of residential buildings: A literature review, Renewable and Sustainable Energy Reviews 52 (2015) 960-975, ISSN 13640321, doi:10.1016/j.rser.2015.07.037

[25] Z. Tian, X. Zhang, X. Jin, X. Zhou, B. Si, X. Shi, Towards adoption of building energy simulation and optimization for passive building design: A survey and a review, Energy and Buildings 158 (2018) 1306-1316, ISSN 03787788, doi:10.1016/j.enbuild.2017.11.022

[26] E. Rodrigues, A. R. Gaspar, Á. Gomes, An approach to the multi-level space allocation problem in architecture using a hybrid evolutionary technique, Automation in Construction 35 (2013) 482-498, ISSN 09265805, doi: 10.1016/j.autcon.2013.06.005.

[27] E. Rodrigues, A. R. Gaspar, Á. Gomes, An evolutionary strategy enhanced with a local search technique for the space allocation problem in architecture, Part 2: Validation and performance tests, Computer-Aided Design 45 (5) (2013) 898-910, ISSN 00104485, doi:10.1016/j.cad.2013.01.003.

[28] E. Rodrigues, A. R. Gaspar, Á. Gomes, An evolutionary strategy enhanced with a local search technique for the space allocation problem in architecture, Part 1: Methodology, Computer-Aided Design 45 (5) (2013) 887-897, ISSN 00104485, doi:10.1016/j.cad.2013.01.001.

[29] E. Rodrigues, A. R. Gaspar, Á. Gomes, Improving thermal performance of automatically generated floor plans using a geometric variable sequential optimization procedure, Applied Energy 132 (2014) 200-215, ISSN 03062619, doi:10.1016/j.apenergy.2014.06.068

[30] E. Rodrigues, A. R. Gaspar, Á. Gomes, Automated approach for design generation and thermal assessment of alternative floor plans, Energy and Buildings 81 (2014) 170-181, ISSN 03787788, doi:10.1016/j.enbuild.2014.06. 016

[31] Ren4EEnIEQ - Comprehensive BIM add-on tool for the improvement of energy efficiency and indoor environment quality in renovation of buildings, URL http://www.adai.pt/ren4eenieq/, 2016.

[32] EnergyPlus Version 8.8 Documentation: Input Output Reference Manual, Tech. Rep., U.S. Department of Energy, URL https://energyplus.net, 2017.

[33] EnergyPlus, URL https://energyplus.net, 2017.

[34] M. Kottek, J. Grieser, C. Beck, B. Rudolf, F. Rubel, World Map of the Köppen-Geiger climate classification updated, Meteorologische Zeitschrift 15 (3) (2006) 259-263, ISSN 09412948, doi:10.1127/0941-2948/2006/0130. 
[35] E. Rodrigues, M. S. Fernandes, A. R. Gaspar, Á. Gomes, J. J. Costa, Dataset of high thermal inertia residential buildings in sixteen Mediterranean locations, doi:10.6084/m9.figshare.5732241. URL https://goo.gl/mfDXCd, 2018.

[36] P. Depecker, C. Menezo, J. Virgone, S. Lepers, Design of buildings shape and energetic consumption, Building and Environment 36 (5) (2001) 627-635, ISSN 03601323, doi:10.1016/S0360-1323(00)00044-5 


\section{Appendix A. Climate information}
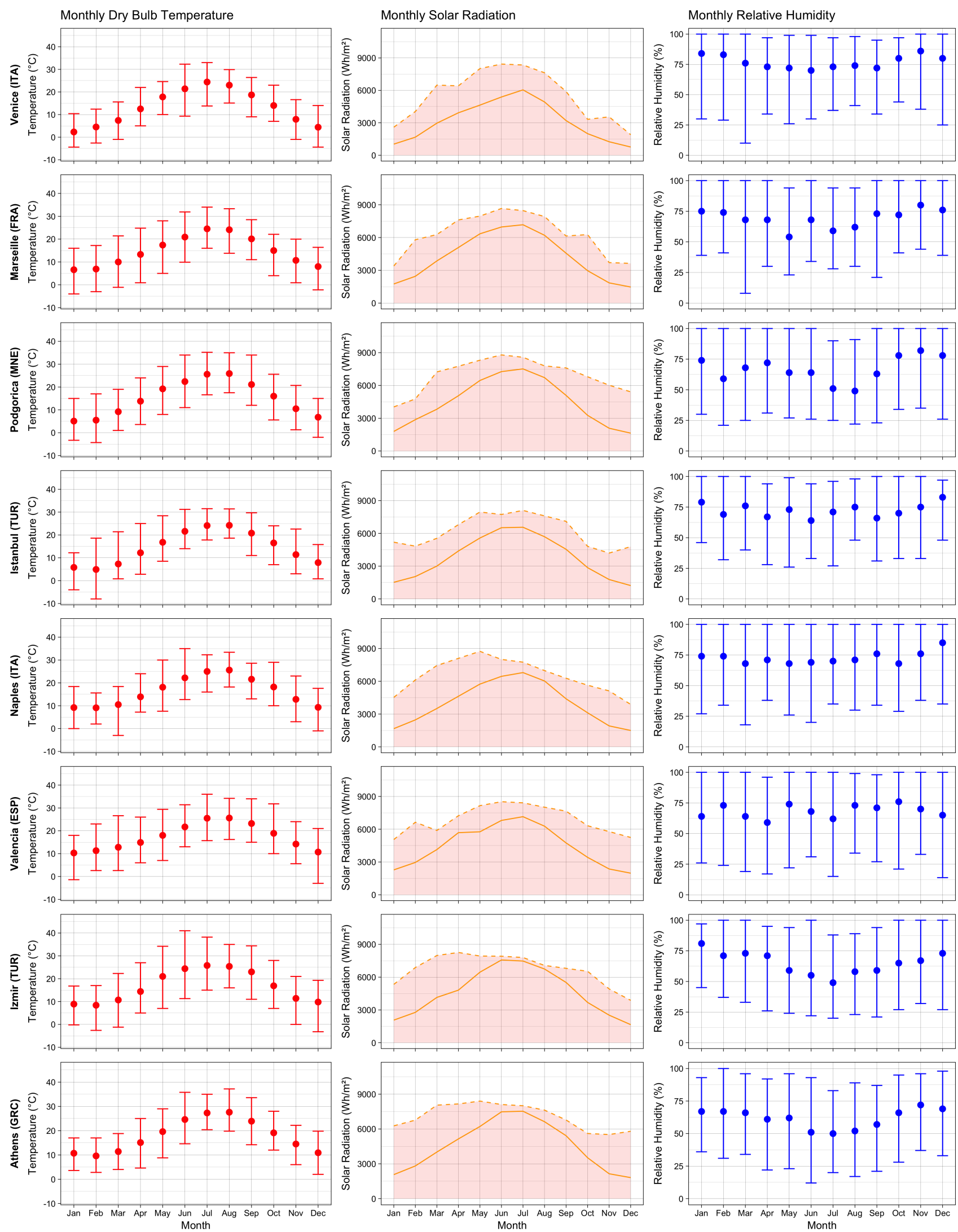

Fig. A.1. Dry bulb temperature, solar radiation and relative humidity per climate location (part 1/2). For solar radiation, the dashed line represents the maximum direct normal solar radiation and the continuous line represents the average global horizontal solar radiation. 

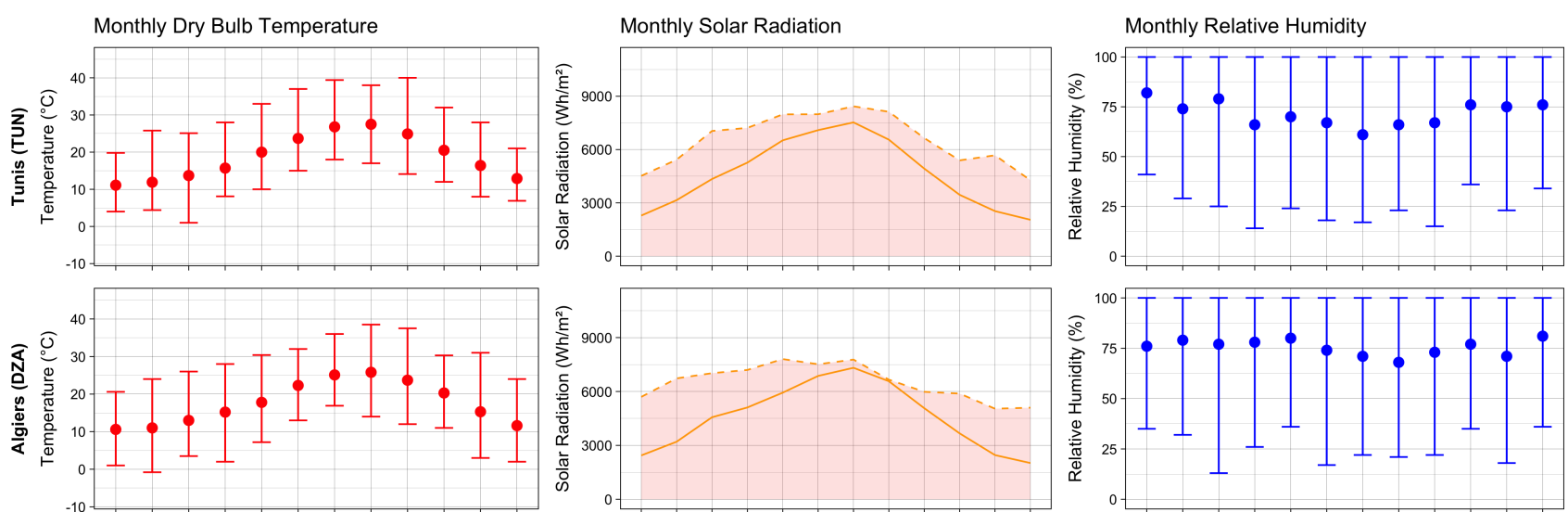

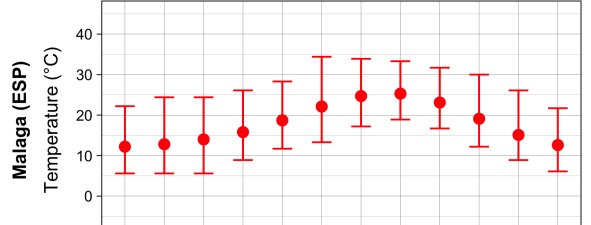
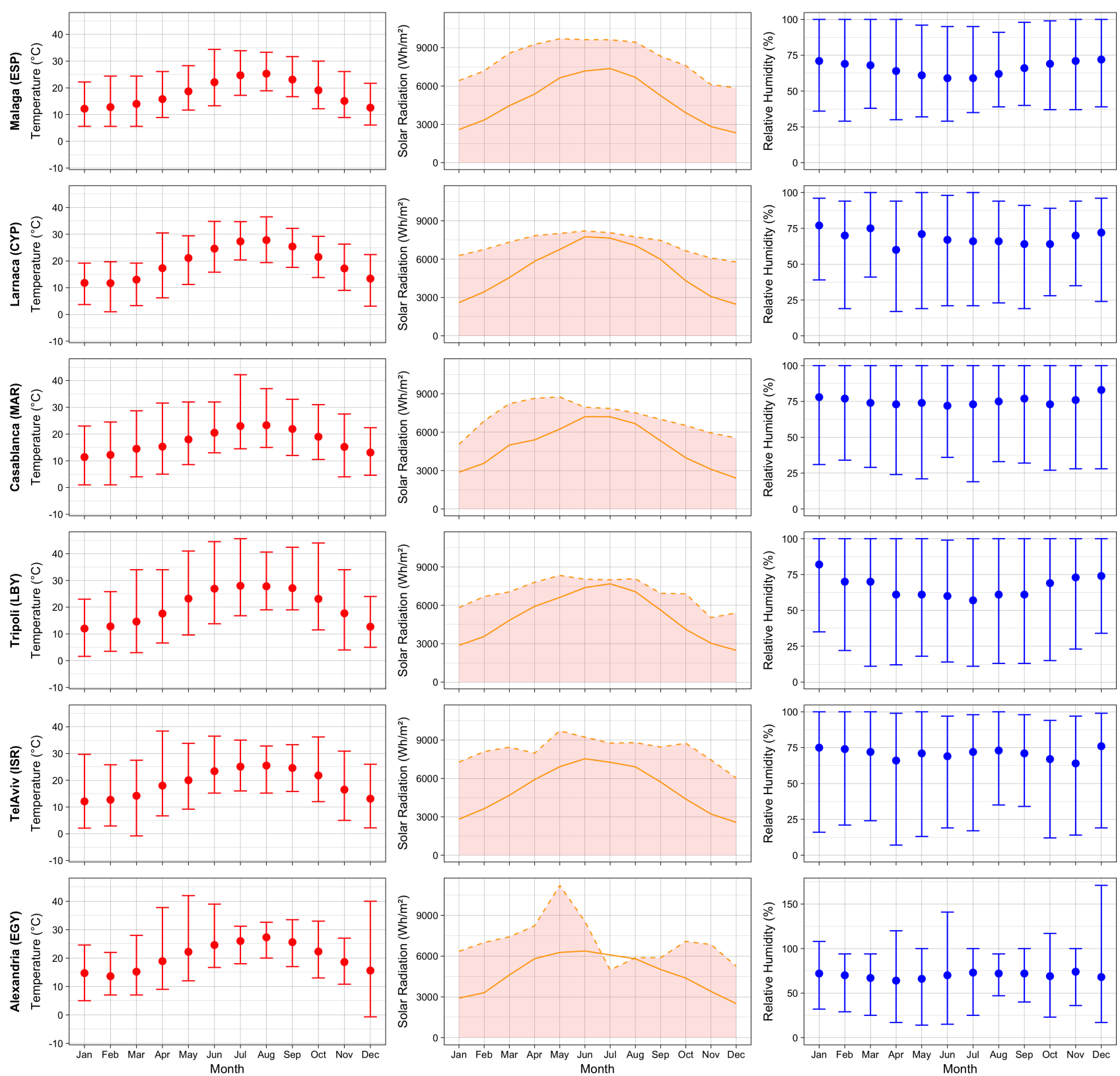

Fig. A.2. Dry bulb temperature, solar radiation and relative humidity per climate location (part 2/2). For solar radiation, the dashed line represents the maximum direct normal solar radiation and the continuous line represents the average global horizontal solar radiation. 